\title{
Hydrothermal corrosion of SiC in LWR coolant environments in the absence of irradiation
}

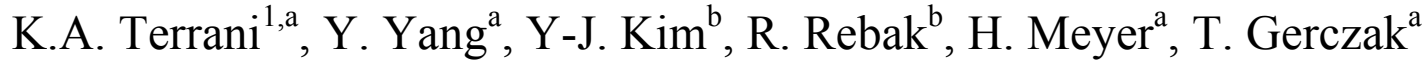 \\ ${ }^{a}$ Oak Ridge National Laboratory, Oak Ridge, TN 37831, USA \\ ${ }^{\mathrm{b}}$ GE Global Research Center, Schenectady, NY 12309, USA
}

\begin{abstract}
Assessment of the thermodynamics of $\mathrm{SiC}$ corrosion under light water reactor coolant environments suggests that silica formation is always expected in the range of applicable $\mathrm{pH}$ and potential. Autoclave testing of SiC-based materials in the absence of ionizing radiation was performed. The kinetics data from these tests, when compared with kinetics of silica dissolution in water and post-exposure characterization of $\mathrm{SiC}$ samples, suggest that oxidation of $\mathrm{SiC}$ to form silica is the rate-limiting step for recession of $\mathrm{SiC}$ in high temperature water. Oxygen activity in water was determined to play an important role in $\mathrm{SiC}$ recession kinetics. A simplified model of a power loop shows the effect of silica dissolution from the hot region (resembling fuel) and deposition in the cold regions.
\end{abstract}

\section{Introduction}

After successful demonstration of $\mathrm{SiC}$ as a stable and effective coating layer in tristructural isotropic (TRISO) fuel particles irradiated in high temperature gas reactors (HTGRs) over the past decades [1-2], this ceramic has been the focus of extensive research for various fission and fusion platform applications. Examples of such applications are structural components in HTGRs and plasma-facing components in fusion reactors that consist of ceramic matrix $\mathrm{SiC} / \mathrm{SiC}$ fiber composites [3-4]. Another nuclear application of $\mathrm{SiC}$ that has received at least a decade of attention is nuclear fuel cladding in light water reactors (LWRs) [5-7]. The technology for these ceramic matrix composites is challenging, and no systematic technology evaluation program has been carried out to date to determine the feasibility of this concept, although key areas of focus have been identified recently [8-9]. One of these key feasibility items is the hydrothermal corrosion of SiC-based materials in LWR coolant environments.

Table 1 provides a summary of LWR coolant water characteristics relevant to LWR core internals for the benefit of the reader. Pressurized water reactors (PWRs) require boron in the coolant water to control the

\footnotetext{
${ }^{1}$ Corresponding author: terranika@ornl.gov, 865-576-0264
}

This manuscript has been authored by UT-Battelle, LLC under Contract No. DE-AC05-00OR22725 with the U.S. Department of Energy. The United States Government retains and the publisher, by accepting the article for publication, acknowledges that the United States Government retains a non-exclusive, paid-up, irrevocable, worldwide license to publish or reproduce the published form of this manuscript, or allow others to do so, for United States Government purposes. The Department of Energy will provide public access to these results of federally sponsored research in accordance with the DOE Public Access Plan (http://energy.gov/downloads/doe-publicaccess-plan). 
core reactivity throughout the irradiation cycle. This is achieved by adding boric acid (up to $2000 \mathrm{ppm}$ ) and controlling the $\mathrm{pH}$ above the neutral point at $\sim 7.2\left(\mathrm{pH}\right.$ neutral water at $300^{\circ} \mathrm{C}$ is 5.6) by also adding a sufficient amount of lithium hydroxide (up to $\sim 6 \mathrm{ppm}$ ). Owing partially to the hydrogen gas on the upper portion of the pressurizer in this system, oxygen activity and, therefore, the electrochemical corrosion potential of the water are quite low. For boiling water reactors (BWRs), the lack of a closed primary loop and the two-phase characteristics of the coolant that travels all the way to the turbines historically resulted in a large oxygen activity in the water and accordingly high corrosion potentials; this coolant chemistry regime is referred to as BWR normal water chemistry (NWC). This hostile environment presented major challenges to the integrity of the fuel and core structural components and was therefore remedied by a series of well thought-out steps that include hydrogen injection, Zn addition, and most recently noble metal chemical addition (NMCA), resulting in what is today largely referred to as BWR hydrogen water chemistry (HWC). Further discussion on the specific role of these additives is beyond the scope of this manuscript and available in other literature [10-12].

Table 1. Summary of LWR coolant water characteristics relevant for LWR fuel and core internals.

\begin{tabular}{|l|c|c|c|}
\hline Condition/Chemistry & PWR & BWR-NWC & BWR-HWC \\
\hline Pressure $(\mathrm{MPa})$ & 15 & 7.5 & 7.5 \\
\hline Temperature $\left({ }^{\circ} \mathrm{C}\right)$ & $320-340$ & $280-290$ & $280-290$ \\
\hline$\left[\mathrm{O}_{2}\right](\mathrm{wt} \mathrm{ppb})$ & $<5$ & $200-1000$ & $<5$ \\
\hline$\left[\mathrm{H}_{2}\right](\mathrm{wt} \mathrm{ppb})$ & $2000-5000$ & 20 & $\sim 200$ \\
\hline $\mathrm{pH}$ & $7-7.4$ & 5.6 & 5.6 \\
\hline Additives & $\begin{array}{c}\mathrm{H}_{3} \mathrm{BO}_{3}, \mathrm{LiOH}, \\
\mathrm{Zn}, \mathrm{noble}^{2} \text { metals }\end{array}$ & $\mathrm{N} / \mathrm{A}$ & $\begin{array}{c}\mathrm{H}_{2}, \mathrm{Zn}, \text { noble } \\
\text { metals }\end{array}$ \\
\hline
\end{tabular}

Corrosion behavior of stoichiometric and high purity $\mathrm{SiC}$ materials (the variants pertinent for nuclear applications) has received ample attention under high pressure, high temperature hydrothermal environments; some examples from the literature among many others are [13-23]. Limited studies on inpile corrosion behavior of SiC-based materials are also available [7].

This manuscript focuses on the corrosion behavior of high purity and crystalline SiC materials in the narrow window of temperature, pressure, and chemistry conditions pertinent to BWRs and PWRs. While some experimental data are provided here, the main goal of this paper is to analyze this information alongside ample prior knowledge with respect to $\mathrm{SiC}$ and $\mathrm{SiO}_{2}$ behavior in water to then develop a mechanistic model that describes the corrosion behavior of $\mathrm{SiC}$ in these environments. Initially, the thermodynamic basis for SiC oxidation in LWR water is analyzed (Sect. 2). Subsequently, limited kinetics data from immersion tests in autoclaves with well-controlled environmental conditions are reported (Sect. 4.1) and post-exposure characterization is carried out (Sect. 4.2). From this information, a mechanistic model for SiC corrosion in LWR environments is then developed (Sect. 5). Also, a simple power loop is modeled where $\mathrm{SiC}$ corrosion results in silica dissolution and advection within the loop (Sect. 6.2). Once the saturated solubility limit of silica in water is reached, it is shown to deposit and build up in the colder regions of the loop. The intent of this example is to develop a straightforward framework for such analyses and show the effect of temperature gradients in the flow loop of the power system. 
Finally, Sect. 6 provides a series of LWR-relevant discussions on the effect of irradiation during in-pile corrosion.

\section{Thermodynamic basis for SiC oxidation in LWR water}

Before kinetics can be discussed, the driving force for the corrosion reaction needs to be quantified. As such, thermodynamic models of pure $\mathrm{SiC}$ in high temperature, high pressure water in a closed system were formulated to identify the resulting products at equilibrium. Specifically, thermo-calc software package with the AQueous Solution database (AQS2) [24] was utilized for extracting thermodynamic quantities and performing equilibrium calculations. The database was developed for calculations of thermodynamic properties of complex aqueous solutions described by the Helgeson-Kirkham-Flowers (HKF) model at conditions of temperatures up to $1000^{\circ} \mathrm{C}$, pressures up to $5 \mathrm{kbar}$, and aqueous concentrations up to $6 \mathrm{M}$.

Figure 1 shows the calculated Pourbaix diagram of $\mathrm{SiC}$ in water at $573 \mathrm{~K}$ and $15 \mathrm{MPa}$. The water dissociation lines are also shown in the figure and, consistent with the convention for calculating lines (a) and (b), the partial pressures of $\mathrm{H}_{2}$ and $\mathrm{O}_{2}$, respectively, are assumed to be $1 \mathrm{~atm}$. It readily becomes obvious that under these conditions, $\mathrm{SiC}$ will react with water to form silica via a number of paths, as identified in Eqs. (1)-(4). While the fate of silicon is fixed (it undergoes oxidation to form silica), as the oxygen activity in the system increases, carbon will manifest as methane, a solid carbon layer, carbon monoxide, or carbon dioxide. Solid carbon is stable over a very narrow region, and original observations of this phenomenon incited much interest in growing a thin carbon layer on the surface of SiC fibers without the need for a chemical vapor deposition process [16, 25-26]. It is worth noting that at a given $\mathrm{pH}$, the reaction path yielding $\mathrm{CO}$ is indeed insignificant for any given potential since at low potentials (low oxygen activity) $\mathrm{CH}_{4}$ is the dominant by-product, which is then replaced swiftly by $\mathrm{CO}_{2}$ as the potential increases.

$$
\begin{aligned}
& \mathrm{SiC}_{(\mathrm{s})}+2 \mathrm{H}_{2} \mathrm{O}_{(\mathrm{aq})} \rightarrow \mathrm{SiO}_{2(\mathrm{~s})}+\mathrm{CH}_{4(\mathrm{~g})}, \\
& \mathrm{SiC}_{(\mathrm{s})}+2 \mathrm{H}_{2} \mathrm{O}_{(\mathrm{aq})} \rightarrow \mathrm{SiO}_{2(\mathrm{~s})}+2 \mathrm{H}_{2(\mathrm{~g})}+\mathrm{C}_{(\mathrm{s})}, \\
& \mathrm{SiC}_{(\mathrm{s})}+3 \mathrm{H}_{2} \mathrm{O}_{(\mathrm{aq})} \rightarrow \mathrm{SiO}_{2(\mathrm{~s})}+3 \mathrm{H}_{2(\mathrm{~g})}+\mathrm{CO}_{(\mathrm{g})}, \\
& \mathrm{SiC}_{(\mathrm{s})}+4 \mathrm{H}_{2} \mathrm{O}_{(\mathrm{aq})} \rightarrow \mathrm{SiO}_{2(\mathrm{~s})}+4 \mathrm{H}_{2(\mathrm{~g})}+\mathrm{CO}_{2(\mathrm{~g})} .
\end{aligned}
$$




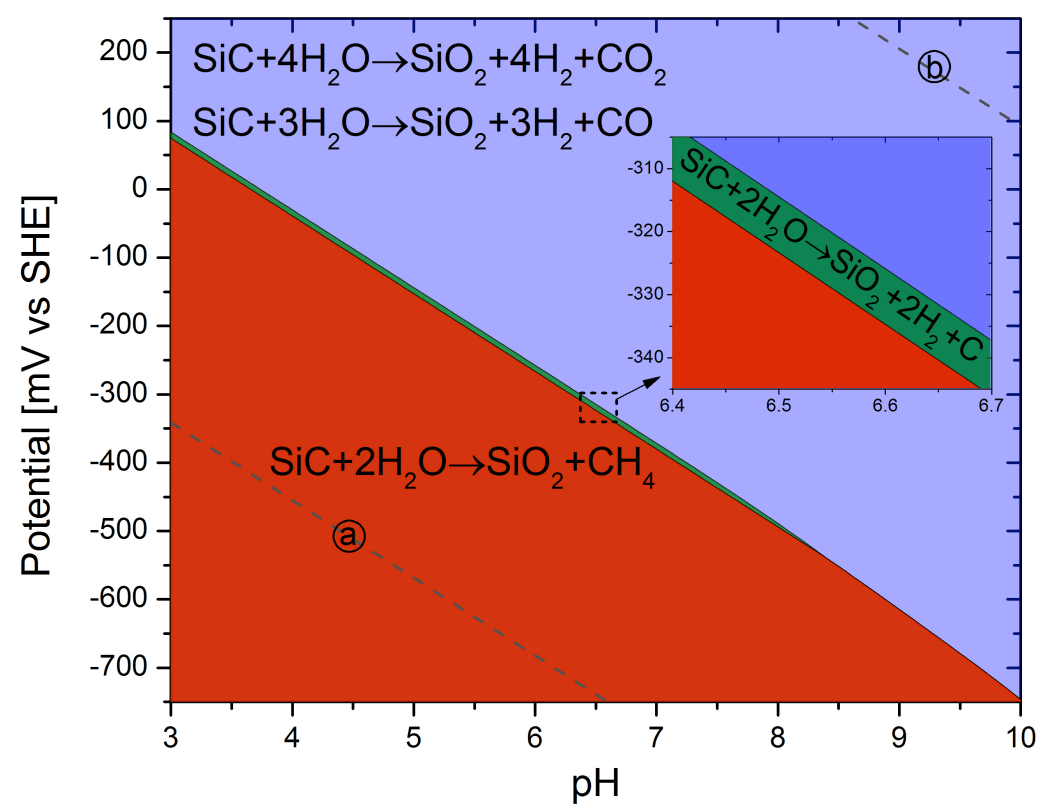

Fig. 1. Pourbaix diagram of $\mathrm{SiC}$ in water at $573 \mathrm{~K}$ and $15 \mathrm{MPa}$; (a) and (b) are water dissociation lines.

Once it is established that $\mathrm{SiC}$ forms silica in all high temperature water environments relevant to LWR coolant conditions, the fate of product silica should now be considered. Fortunately, a great deal of research has been dedicated to this area, particularly in the field of geochemistry. It is established that just as in the case of exposure to steam [27-29], silica reacts with the water molecules in hydrothermal environments to form $\mathrm{Si}(\mathrm{OH})_{4}$, which itself then undergoes hydrolysis to result in aqueous silicic acid [30-37]. The overall reaction is

$\mathrm{SiO}_{2(\mathrm{~s})}+2 \mathrm{H}_{2} \mathrm{O}_{(\mathrm{aq})} \rightleftharpoons \mathrm{Si}(\mathrm{OH})_{4(\mathrm{aq})}$

The solubility limit of silica in water varies greatly as a function of temperature and the crystal structure of the solid silica phase [30,32]. Solubility limit increases with temperature, and amorphous silica exhibits the largest solubility limit after cristobalite and then quartz. It should be noted that for the purposes of nuclear applications, the relevant structure is amorphous silica since all the crystalline variants readily amorphize in the presence of irradiation [38]. Increasing system pressure stabilizes the liquid phase of water while also increasing the solubility limit of silica in water. The effect of $\mathrm{pH}$, certainly within the range pertinent to LWR environments, is deemed negligible on the solubility limit of silica in water [31]. The effect of $\mathrm{pH}$ becomes pronounced under alkaline conditions $(\mathrm{pH}>8)$, resulting in a rapid increase in the solubility limit of silica [39]. This is the case because silicic acid can dissociate and lose up to two protons to form hydrogen ions; detailed explanation and reaction rate constants are available in $[34,40]$. Figure 2 shows the solubility limit for $\mathrm{SiO}_{2}$ (amorphous and quartz allotropes) in neutral water as a function of temperature and pressure. Note that the overall solubility limit is quite high and increases rapidly over the narrow temperature range of this figure, which was chosen intentionally to be applicable for LWR coolant environments. It is worthwhile to note that the current water chemistry guidelines issued annually by the Electric Power Research Institute limit the amount of dissolved silica in LWR coolant to 1 ppm [41], roughly three orders of magnitude lower than the limits in Fig. 2. 


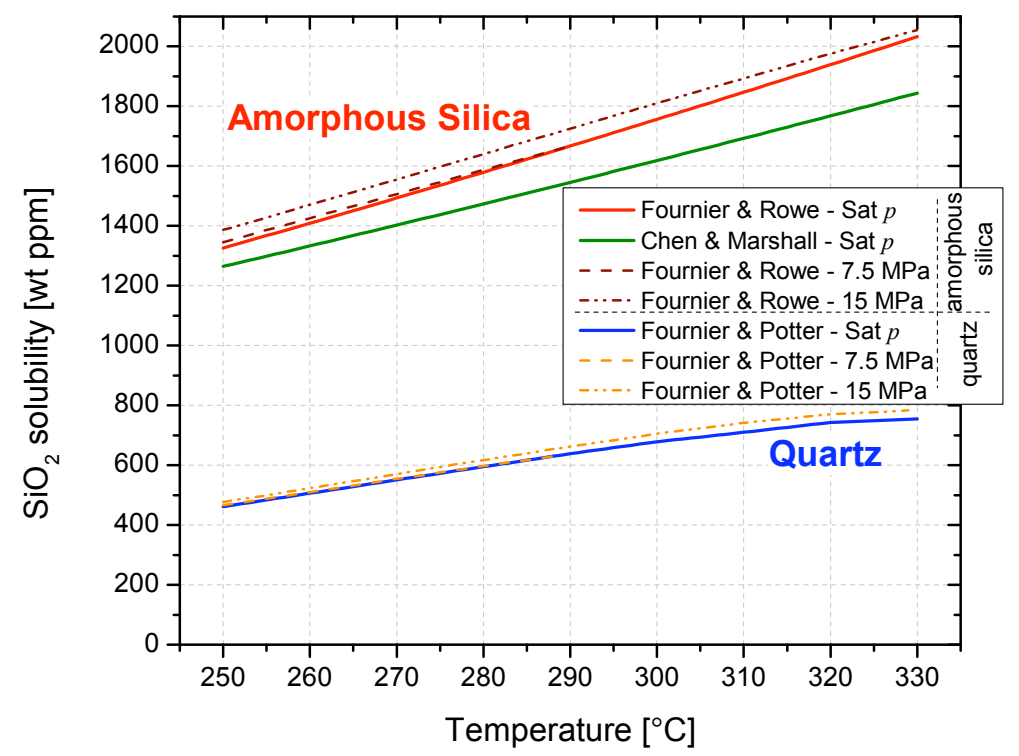

Fig. 2. Solubility limit of amorphous silica and quartz in high temperature neutral water as a function of temperatures and pressures of LWR coolant environments [30, 32, 42].

\section{Experimental details}

Tow $\mathrm{SiC}$ material variants and amorphous (fused) silica underwent immersion tests in 3.781 (1 gallon) 316 stainless steel (SS) autoclaves at GE Global Research Center (Schenectady, NY). The immersion tests were performed in a simulated PWR water chemistry for three months and in simulated BWR-HWC and BWR-NWC water chemistries for two months with details of the environmental conditions provided in Table 2. No boric acid and $\mathrm{LiOH}$ were added to a simulated PWR water chemistry condition. Fused silica specimens were also tested for a shorter duration, 5 days, under BWR-NWC simulated conditions (water at $288^{\circ} \mathrm{C}$, containing $2 \mathrm{ppm}$ of dissolved oxygen).

Table 2. Summary of autoclave conditions for immersion tests.

\begin{tabular}{|l|c|c|c|c|c|}
\hline \multicolumn{1}{|c|}{ Autoclave } & Chemistry & $\begin{array}{c}\text { Temperature } \\
\left({ }^{\circ} \mathbf{C}\right)\end{array}$ & $\mathbf{p H}$ & $\begin{array}{c}\text { Redox Potential } \\
(\mathbf{m V} \text { vs SHE) }\end{array}$ & $\begin{array}{c}\text { Pressure } \\
\mathbf{( M P a})\end{array}$ \\
\hline PWR & $3.57 \mathrm{ppm} \mathrm{H}_{2}$ & 330 & 7.2 & -820 & 15 \\
\hline BWR-HWC & $0.3 \mathrm{ppm} \mathrm{H}_{2}$ & 290 & 5.6 & -540 & 7 \\
\hline BWR-NWC & $1.0 \mathrm{ppm} \mathrm{O}_{2}$ & 290 & 5.6 & 350 & 7 \\
\hline
\end{tabular}

The SiC variants consisted of chemical-vapor-deposited (CVD) monolithic SiC and chemical-vaporinfiltrated (CVI) SiC matrix reinforced with $\mathrm{SiC}$ fiber ( $\mathrm{SiC} / \mathrm{SiC}$ ) composites. The CVD variant, of purity $>99.999 \%$, was purchased from Dow Chemical Co. (Marlborough, MA). The CVI SiC/SiC composite specimens consisted of Hi-Nicalon ${ }^{\mathrm{TM}}$ Type-S (HNLS) SiC fiber inside a SiC matrix manufactured by Hyper-Therm High Temperature Composites (presently Rolls-Royce High Temperature Composites, Huntington Beach, CA). Prior to matrix infiltration, the fibers were coated with four 20 -nm-thick pyrolytic carbon $(\mathrm{PyC})$ and 100-nm-thick $\mathrm{SiC}$ alternating layers, constituting the fiber-matrix interphase. The CVD-SiC and silica specimens consisted of rectangular $18 \times 6 \times 0.5 \mathrm{~mm}$ bars and the $\mathrm{SiC} / \mathrm{SiC}$ 
composites were $12 \times 12 \times 2 \mathrm{~mm}$ bars.. All samples, which contained a hole of 1-3 mm diameter, were arranged and hung on a polytetrafluorethylene (PTFE) insulated 304 SS wire with a PTFE spacer between specimens to avoid physical contact between them during the immersion tests. The surfaces of the $\mathrm{SiC} / \mathrm{SiC}$ composite specimens were fully coated with $\mathrm{SiC}$ during the CVI process to eliminate any fibermatrix interphase exposure to the corrosive environment.

The water in the test loop was purified through a demineralizer, an organic removal column, and a submicron filter before passing into a 3.781 glass conditioning column. The water was then equilibrated with appropriate mixtures of $\mathrm{Ar}, \mathrm{O}_{2}$, and $\mathrm{H}_{2}$ to establish the desired water chemistry at a water flow rate of $200 \mathrm{cc} / \mathrm{min}$. SWAN FAM Oxytrace and Hach Orbisphere Model 26322 monitors were used for measuring the dissolved oxygen and hydrogen, respectively, in the inlet and outlet streams. A platinum flag electrode was used to monitor the effective redox potential of the water with an Agilent 34970A Electrometer using a zirconia high temperature $\mathrm{pH}$ sensor with a copper/cuprous oxide internal junction $\left(\mathrm{ZrO}_{2} / \mathrm{Cu} / \mathrm{Cu}_{2} \mathrm{O}\right)$ as a reference electrode at high temperature. The electrochemical potential in each autoclave is calculated by using the temperature, pressure, $\mathrm{pH}$, and dissolved gas information for each system as shown in Fig. 3. The samples were extracted from the autoclaves once a month, cleaned in a high purity water for a few minutes ultrasonically, dried at the laboratory temperature $\left(\sim 23-25^{\circ} \mathrm{C}\right)$, and weighed to determine the extent of mass change as a result of corrosion. The mass change was reported as the average change in mass from three specimens of each material in each water chemistry condition.

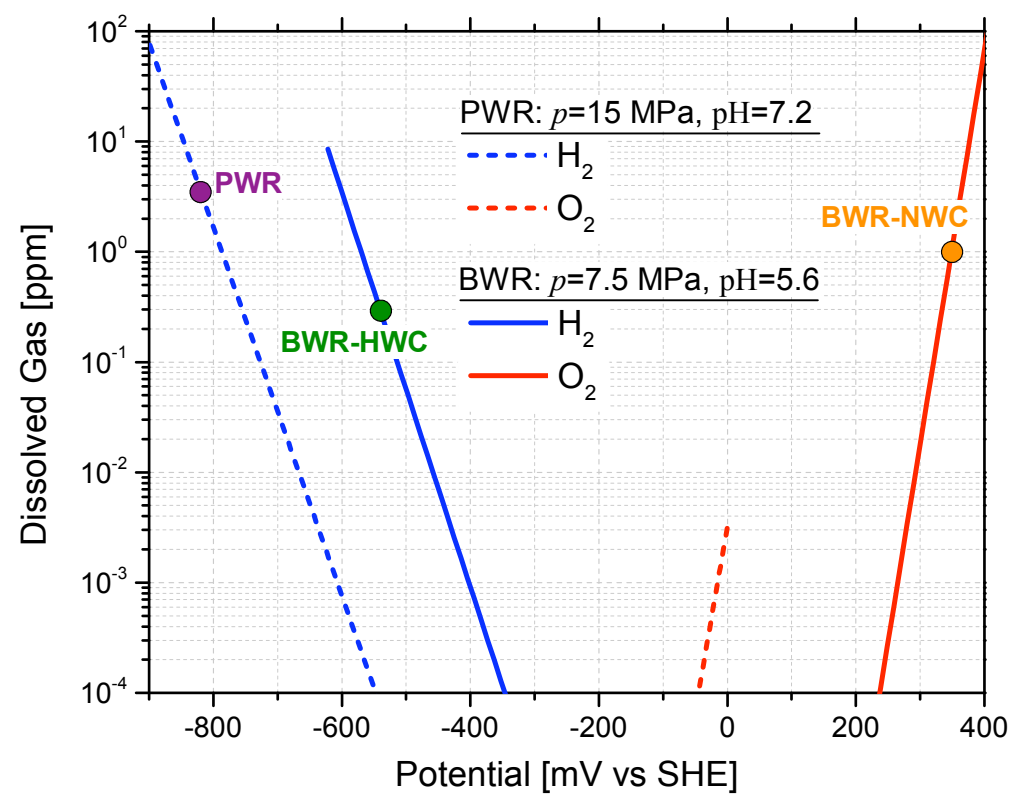

Fig. 3. Dissolved hydrogen and oxygen as a function of potential inside the PWR and BWR autoclaves.

After the immersion test and weight measurement were completed, the specimens were further characterized at ORNL in order to examine the surface morphology and degradation behavior of test specimens. Scanning electron microscopy (SEM) analysis was conducted with a JEOL 6500 FEG-type microscope operating at an accelerating potential of $15 \mathrm{kV}$. Electron backscatter diffraction (EBSD) analysis was conducted on the JEOL 6500 SEM using EDAX's TSL OIM Analysis 7 package. EBSD acquisition conditions were $15 \mathrm{kV}$ accelerating potential, $25 \mathrm{~mm}$ working distance, and $0.2 \mu \mathrm{m}$ step size. Scans were acquired from a $300 \mu \mathrm{m} \times 300 \mu \mathrm{m}$ area, and patterns were indexed against a silicon carbide 
$3 \mathrm{C}$ reference. Data processing involved a single-iteration grain dilation with a minimum grain size of four data points and grain tolerance of 5 degrees. X-ray diffraction (XRD) studies were performed with a Rigaku MiniFlex Ii XRD instrument of $0.45 \mathrm{~kW}(30 \mathrm{kV}$ and $15 \mathrm{~mA}$ ) with $\mathrm{Cu}-\mathrm{K} \alpha$ radiation. X-ray photoelectron spectroscopy (XPS) was carried out on a Thermo Scientific K-Alpha XPS instrument with $\mathrm{X}$-ray spot diameter of $400 \mu \mathrm{m}$. XPS depth profiles were acquired with a $2 \mathrm{kV}$ Ar-ion beam operated at current that gave a sputter etch rate of $\sim 13 \mathrm{~nm} / \mathrm{min}$.

\section{Results}

\subsection{Autoclave corrosion kinetics}

Figure 4 shows the weight change of the CVD-SiC specimens as a function of immersion time in three different water chemistry conditions. The data suggest that mass loss increases with the oxygen activity in the system. The thickness loss of CVD-SiC is also specified on the right axis of Fig. 4 and was calculated on the basis of a $\mathrm{SiC}$ density of $3.2 \mathrm{~g} / \mathrm{cm}^{3}$. However, the mass change of CVI SiC/SiC composites proved quite different, as shown in Fig. 5, where a mass gain was measured, at least after short-term immersion tests. The mass gain in the $\mathrm{SiC} / \mathrm{SiC}$ specimens may be explained by penetration of liquid into the composite fiber planes, although this was not expected by the overcoating of the specimens and no evidence for it was found with limited investigation, as discussed in the later sections. It may be postulated that some oxide debris that were introduced from the SS autoclave and tubing surfaces exposed to high temperature water, may not have been completely removed during the ultrasonic cleaning process.

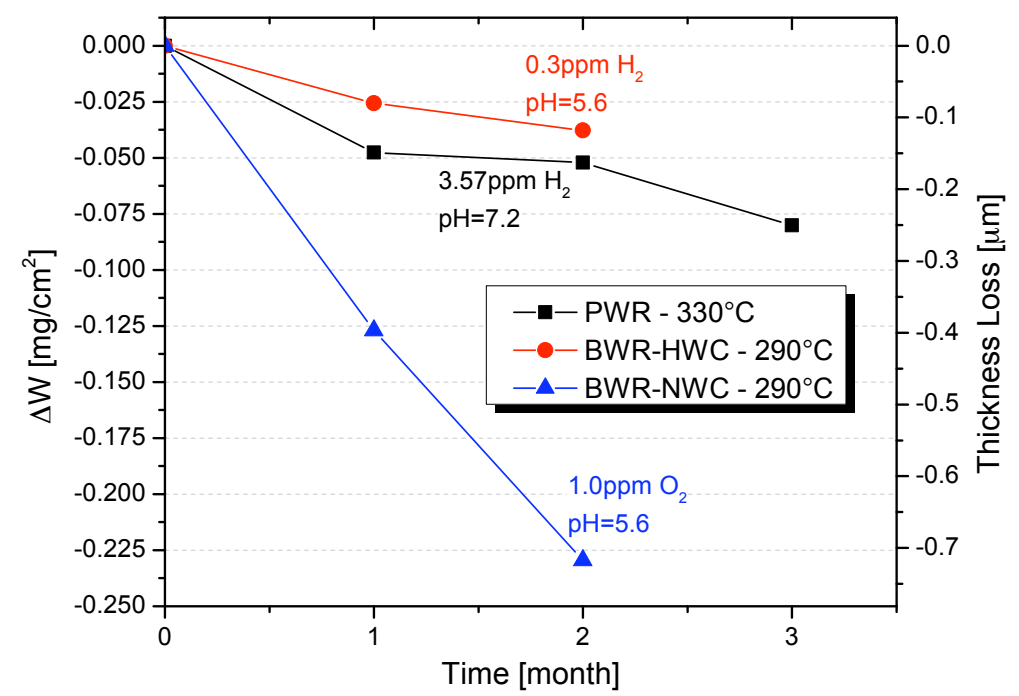

Fig. 4. Mass change in CVD-SiC after autoclave immersion. 


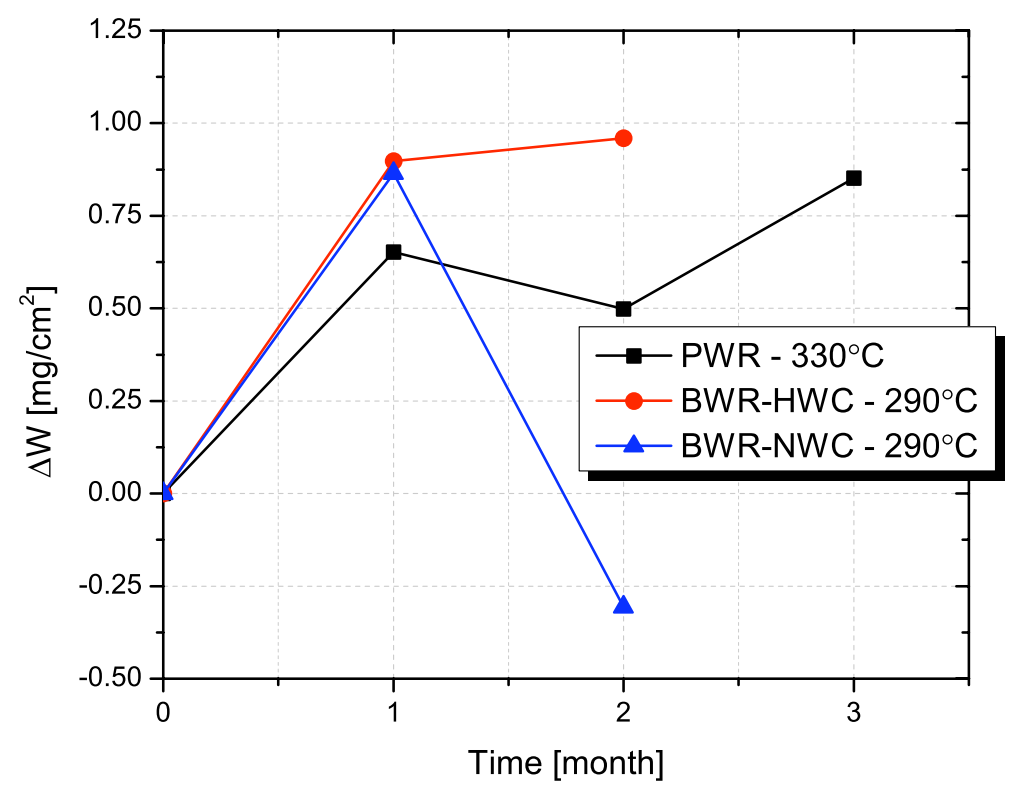

Fig. 5. Mass change in $\mathrm{CVI} \mathrm{SiC/SiC} \mathrm{composites} \mathrm{after} \mathrm{autoclave} \mathrm{immersion.}$

None of the 500- $\mu \mathrm{m}$-thick fused silica specimens survived after one month of exposure in any of the autoclave tests (they all physically disappeared). Therefore, a separate set of shorter-term tests were performed inside a $288^{\circ} \mathrm{C} 2$ ppm $\mathrm{O}_{2} \mathrm{BWR}-\mathrm{NWC}$ autoclave to determine the dissolution kinetics. As shown in Fig. 6, a linear mass loss was observed; however, it did not follow the expected mass loss behavior of specimens disappeared after exposure for 1 month in $290^{\circ} \mathrm{C}$ water containing $1 \mathrm{ppm} \mathrm{O}_{2}$ or in other two hydrogen water chemistry conditions. Nonetheless, the mass loss rate of fused silica proved much faster than CVD-SiC. It is possible that prior to complete disappearance (dissolution) of the specimens during the one-month exposure tests, they broke off from the hang wire.

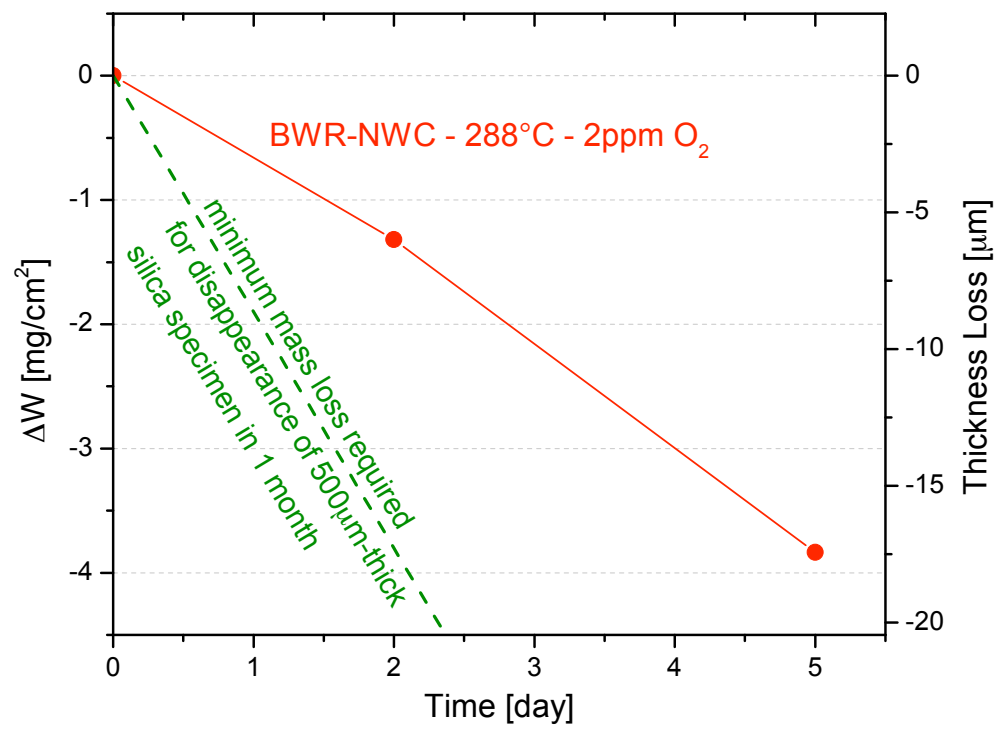

Fig. 6. Fused silica mass loss after BWR-NWC autoclave immersion. 


\subsection{Post-exposure characterization}

\subsubsection{X-ray diffractometry}

After the autoclave exposures were complete, the CVD-SiC and $\mathrm{SiC} / \mathrm{SiC}$ composite specimens were initially examined via XRD. Consistent with prior studies by Hirayama et al. [14] and Kim et al. [18], no sign of any oxides was found on the surface of the specimens and the depiction of the spectra are therefore omitted from this paper. It is worth noting that a strong texture was observed in the SiC grains of the CVI composite. Given that the interaction of water molecule with SiC surface is known to differ across different crystallographic planes [43], the presence of this strong texture could result in different corrosion kinetics in these materials.

\subsubsection{X-ray photoelectron spectroscopy}

XPS study on the surface of all CVD-SiC and $\mathrm{SiC} / \mathrm{SiC}$ composite specimens was carried out. Initially a wide energy range survey spectrum was acquired, and no unexpected surface species were found to be present except for a small amount of $\mathrm{Ni}$ at $\sim 1$ at $\%$ for PWR and BWR-HWC exposed specimens and up to 8 at $\%$ for BWR-NWC exposed specimens. Following this step, narrow energy region core level spectra that were focused on $\mathrm{C} 1 \mathrm{~s}, \mathrm{O} 1 \mathrm{~s}$, and $\mathrm{Si} 2 \mathrm{p}$ energy ranges were acquired. Following the acquisition of core level spectra at each analysis spot, ion sputter etching was performed for $15 \mathrm{~s}$, the equivalent of removing $\sim 5 \mathrm{~nm}$ of material, and a new set of core level spectra was acquired once again. Finally, a new area was selected and Ar-ion sputter depth profiles were acquired down to a depth of 200 to $400 \mathrm{~nm}$. The depth scale was determined by using sputtering time multiplied by a known sputter rate $(13 \mathrm{~nm} / \mathrm{min})$ previously measured on standard $\mathrm{SiO}_{2}$ films.

Figure 7 shows the core level spectra for $\mathrm{C} 1 \mathrm{~s}, \mathrm{O} 1 \mathrm{~s}$, and $\mathrm{Si} 2 \mathrm{p}$ on the surface of a CVD-SiC specimen after the PWR immersion test; the result is essentially identical to those from all other SiC samples after PWR and BWR-HWC immersion tests. Consistent with the previous Auger electron spectroscopy [14] and XPS [44] results reported from water-corroded SiC specimens, no sign of silica layer formation was observed on the surface of $\mathrm{SiC}$ samples. In Fig. 7 the red curves correspond to the as-exposed surface and the blue curves were obtained from the light sputter etch surface (all spectra have been normalized to the same height to compare peak positions and shapes). The as-exposed surface shows an oxidized form of carbon, most likely $\mathrm{C}-\mathrm{O}$, while no distinct $\mathrm{Si}-\mathrm{O}$ feature is apparent in the $\mathrm{Si} 2 \mathrm{p}$ spectrum. The light sputtering has two effects: First, the oxidized carbon is removed and the main peak (belonging to $\mathrm{C}-\mathrm{Si}$ bonds) shifts slightly to higher binding energy and broadens. Second, the Si $2 p$ peak shifts to slightly lower binding energy and broadens following the sputtering. The changes to the Si and $\mathrm{C}$ peaks are likely the result of ion-induced damage or introduced surface defects. The signal from the small amount of oxygen on the surface, corresponding to $\mathrm{O} 1 \mathrm{~s}$, is a mix of mainly $\mathrm{O}-\mathrm{C}$ with some $\mathrm{O}-\mathrm{Ni}$, and $\mathrm{O}-\mathrm{Si}$ species. The specimens exposed to BWR-NWC conditions showed similar features except that the $\mathrm{C}-\mathrm{O}$ peak did not disappear after light sputtering and was only reduced. However, even in the case of these specimens, the Si $2 p$ spectrum consisted solely of $\mathrm{Si}-\mathrm{C}$ associated bonds. 


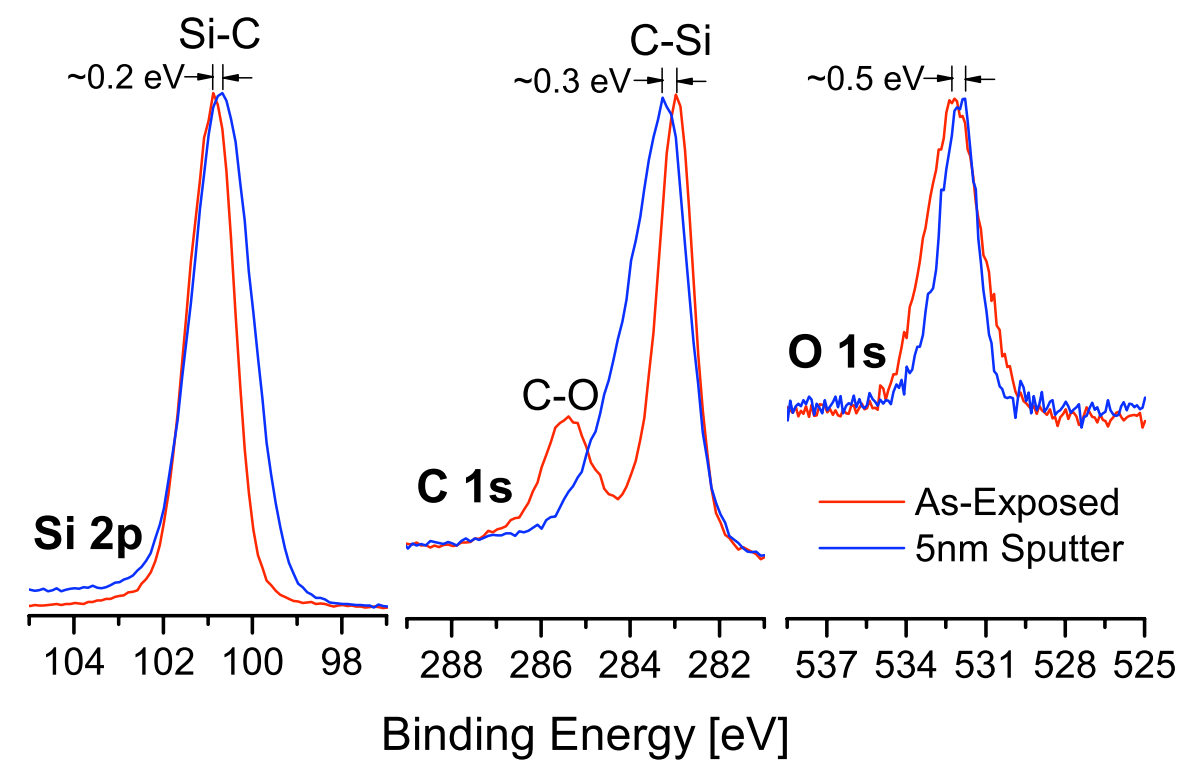

Fig. 7. XPS spectra of the CVD-SiC surface after the PWR immersion test. These spectra are representative of observations for other PWR and BWR-HWC immersion-tested CVD-SiC and SiC/SiC specimens.

The results from depth profiling the same specimen as in Fig. 7, along with the BWR-NWC exposed $\mathrm{SiC} / \mathrm{SiC}$ specimen, are shown in Fig. 8. Once again, the PWR exposed CVD-SiC is representative of the results for all other specimens exposed under PWR and BWR-HWC conditions. In the case of the PWR exposed CVD-SiC specimen, initial sputtering decreases the C concentration slightly (removal of non-Si bound carbon species). Essentially, the surface that was depleted in $\mathrm{Si}$, as reported previously [19], is etched away. Likewise, the $\mathrm{O}$ signal decreases as $\mathrm{O}$-bound species $(\mathrm{O}-\mathrm{C}, \mathrm{O}-\mathrm{Ni}$, and $\mathrm{O}-\mathrm{Si}$ ) are removed. Removal of the surface species containing $\mathrm{C}$ and $\mathrm{O}$ results in a slight increase in Si signal. A different picture is present for the BWR-NWC exposed $\mathrm{SiC} / \mathrm{SiC}$ specimen, where the large amount of oxygen present on the surface is reduced only slightly with subsequent sputtering. In fact, additional sputtering to a depth of $\sim 700 \mathrm{~nm}$ shows little change from that shown for the CVD-SiC specimen in Fig. 8. 


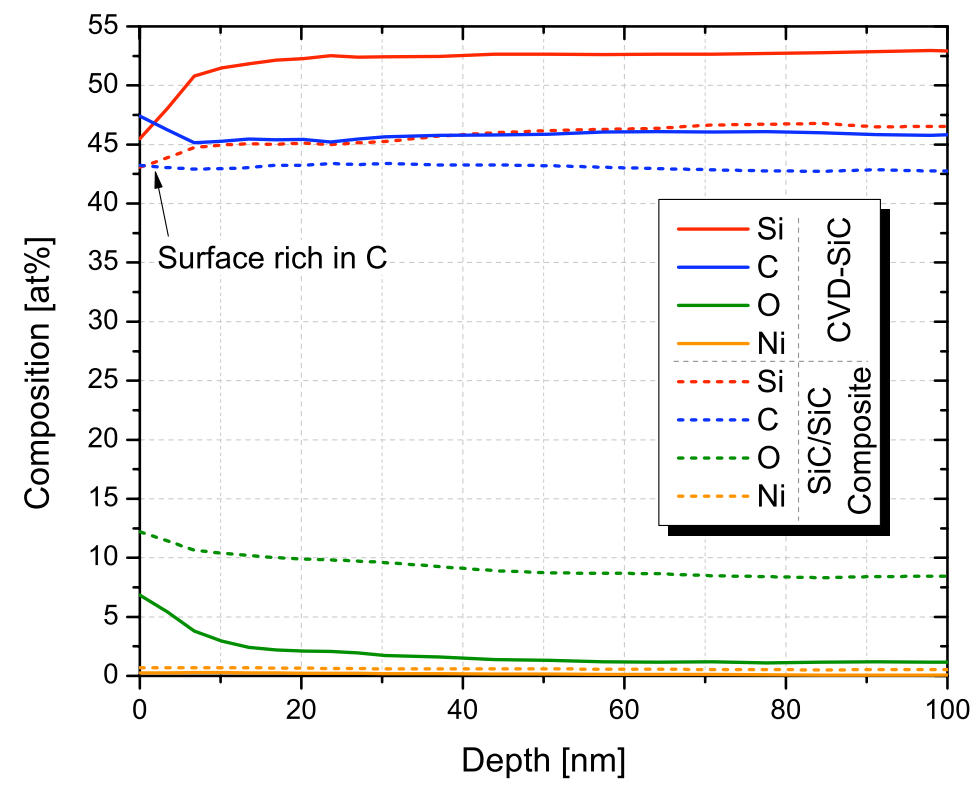

Fig. 8. XPS depth profile of $\mathrm{Si}, \mathrm{C}$, O, and $\mathrm{Ni}$ on the surface of a CVD-SiC and a $\mathrm{SiC} / \mathrm{SiC}$ composite specimen after PWR and BWR-NWC immersion tests, respectively.

\subsubsection{Scanning electron microscopy}

Figure 9 shows the surface characteristics of $\mathrm{SiC}$ specimens prior to and after the various immersion tests. In the case of CVD-SiC, after PWR and BWR-HWC exposures, the material is selectively removed and dissolved away. In the case of the BWR-NWC exposed specimen, the material loss is greatly pronounced and appears to occur particularly at the grain boundaries. Surface features are much different for $\mathrm{SiC} / \mathrm{SiC}$ composite specimens, where no distinct grain boundary pattern is apparent in the lower-resolution images. This is the case because, as indicated in Fig. 9(i), the $\mathrm{SiC}$ matrix of the $\mathrm{SiC} / \mathrm{SiC}$ composites consists of small columnar grains with lengths of $\sim 1 \mu \mathrm{m}$ and diameters on the order of a few hundred nanometers. Therefore, the general macroscopic surface features are preserved in the PWR and BWRHWC immersion tests. However, after the two month immersion in BWR-NWC conditions, extensive dissolution of the surface, resulting in its flattening, can be observed. Figure 10 shows the cross section of the $\mathrm{SiC} / \mathrm{SiC}$ composite specimens. The limited area investigated in this figure (and accompanying EDS data not included here) suggest that no sign of water ingress and internal oxidation is apparent; ruling out this phenomena as explanation for the observed mass gain in these samples in Fig. 5. SEM images of the fused silica specimens after 2 and 5 day exposures are omitted since, as one can expect, the amorphous material undergoes uniform recession. 


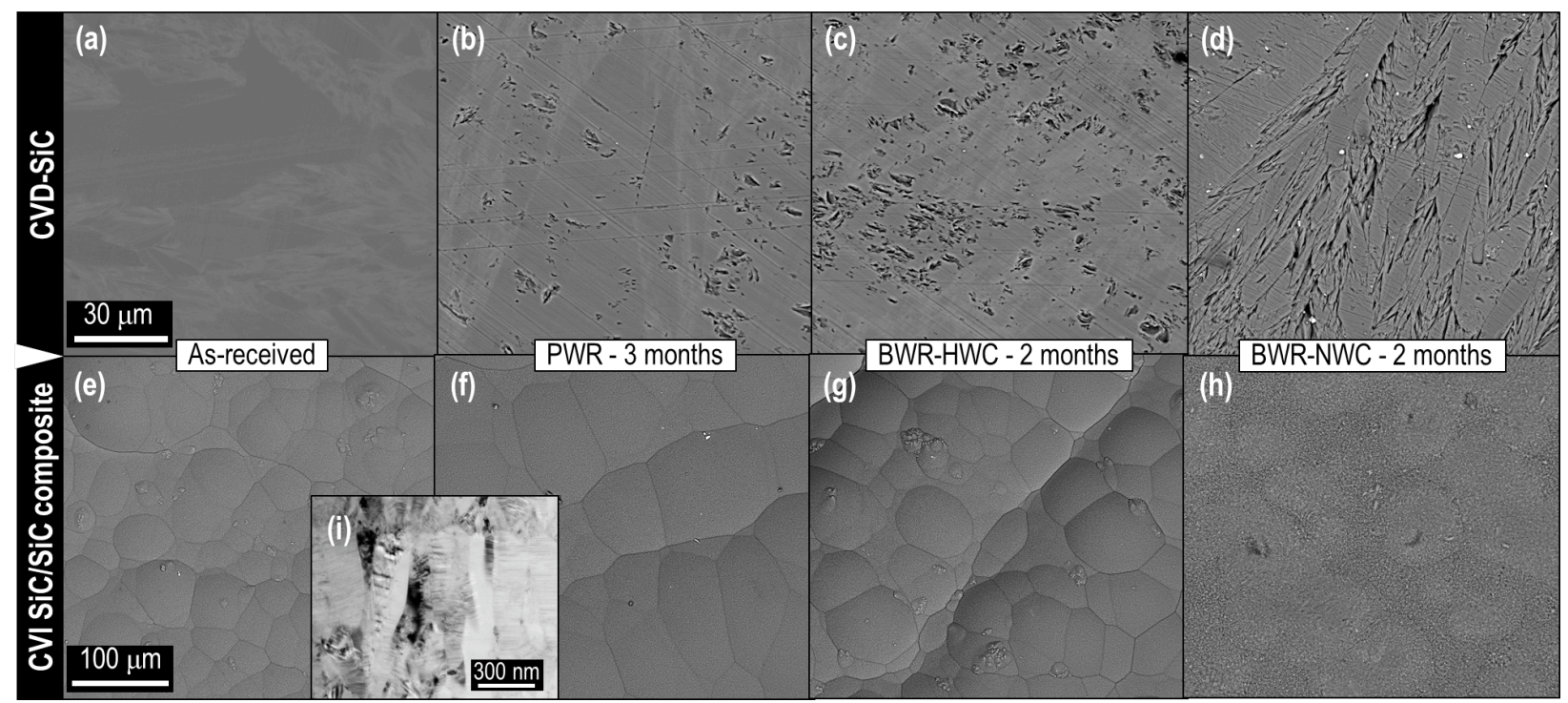

Fig. 9. Backscattered electron image of the surface of as-received CVD-SiC without machining marks (a) and after PWR (b), BWR-HWC (c), and BWR-NWC (d) tests. Backscattered electron image of the surface of as-received $\mathrm{SiC} / \mathrm{SiC}(\mathrm{e})$ and after PWR (f), BWR-HWC (g), and BWR-NWC (h) tests. Bright field transmission electron microscope image of the grain structure of $\mathrm{SiC} / \mathrm{SiC}$ composite matrix (i).

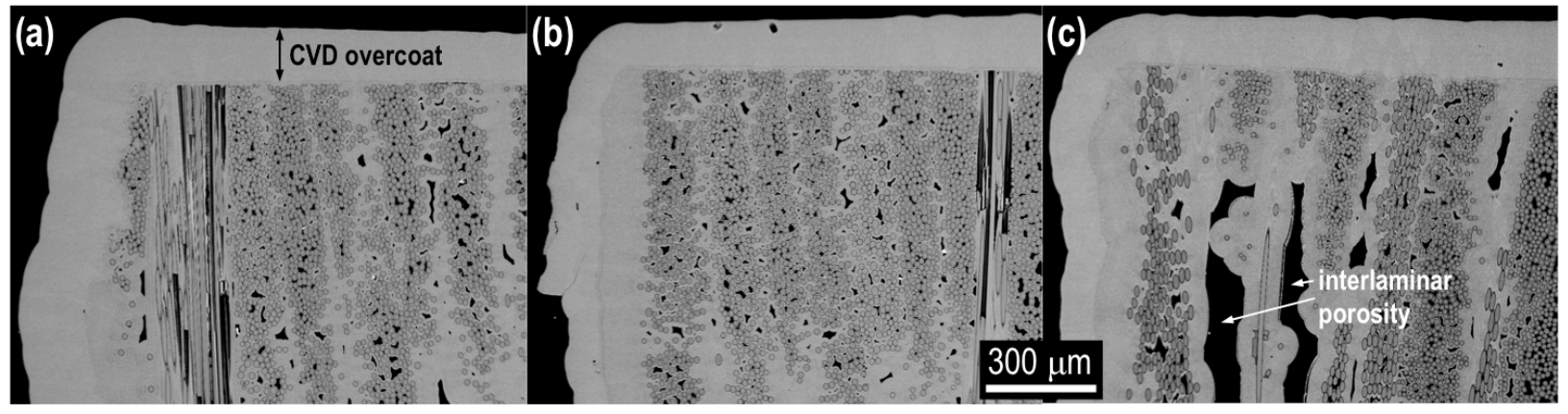

Fig. 10. Backscattered electron image of the cross section of $\mathrm{SiC} / \mathrm{SiC}$ composites after PWR (a), BWR-HWC (b), and BWR-NWC (c) exposures. The limited areas investigated in these cross-sections appear to imply that CVD overcoat layer protects the composite interior from water ingress.

Figure 11 shows the energy-dispersive X-ray spectroscopy (EDS) results acquired from the surface of the exposed samples while conducting the SEM study. All the normalized spectra are largely identical except for the BWR-NWC exposed $\mathrm{SiC} / \mathrm{SiC}$ specimen, in which the presence of oxygen and a small amount of nickel is clearly apparent. 


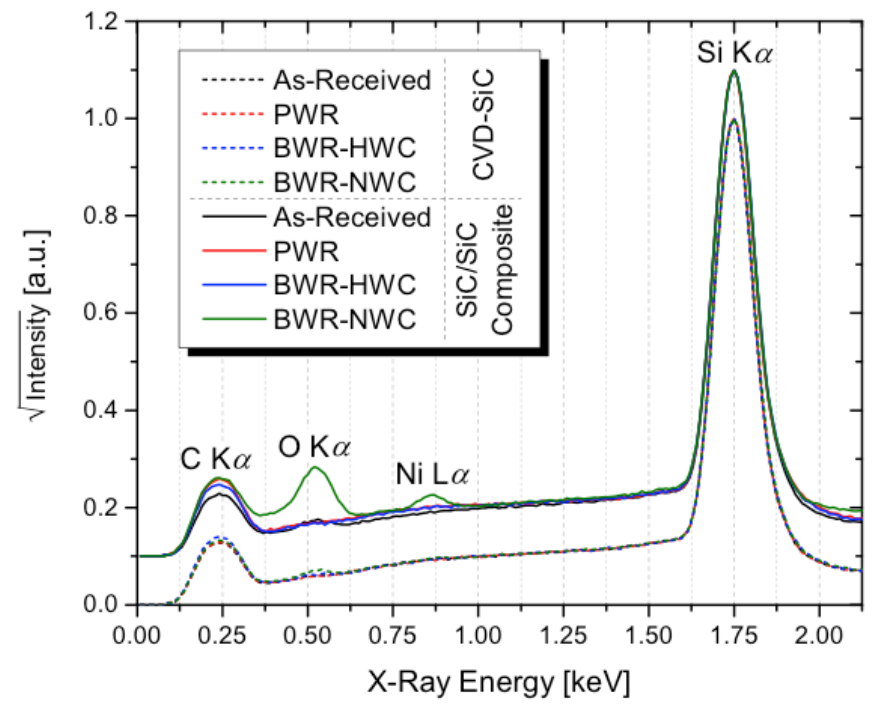

Fig. 11. Energy-dispersive $\mathrm{X}$-ray spectra from the surface of $\mathrm{CVD}-\mathrm{SiC}$ and $\mathrm{SiC} / \mathrm{SiC}$ composite specimens before and after LWR corrosion tests. All spectra are normalized and the $\mathrm{SiC} / \mathrm{SiC}$ results are arbitrarily shifted upward for clarity.

The SEM analysis shown in Fig. 9 indicates preferential dissolution along grain boundaries and in the fine grain areas of the CVD-SiC material. EBSD analysis was implemented to gain insight on the role of grain boundary character on the observed $\mathrm{SiC}$ surface dissolution. Grain boundary character has been shown to influence material performance regarding properties such as corrosion resistance [45], where high angle grain boundaries are more susceptible to attack than low angle and special coincidence site lattice (CSL) grain boundaries. Grain boundary character was determined for grain boundaries that remained intact after autoclave exposure. Intact grain boundaries were identified as those showing limited grain boundary grooving between two indexed grains in the SEM analysis and high index quality patterns across the grain boundary. Figure 12 shows an inverse pole figure map overlaid on an image quality map and highlights examples of intact grain boundaries; the data are partitioned to remove low confidence and low image quality data points that should correspond to localized dissolution of the $\mathrm{SiC}$ surface. The limited analysis (33 total grain boundaries) indicated no strong preference for grain boundary character regarding SiC dissolution, with approximately $33 \%$ of intact grain boundaries being special CSL or low angle boundaries and $\sim 67 \%$ of identified grain boundaries being high angle grain boundaries. 


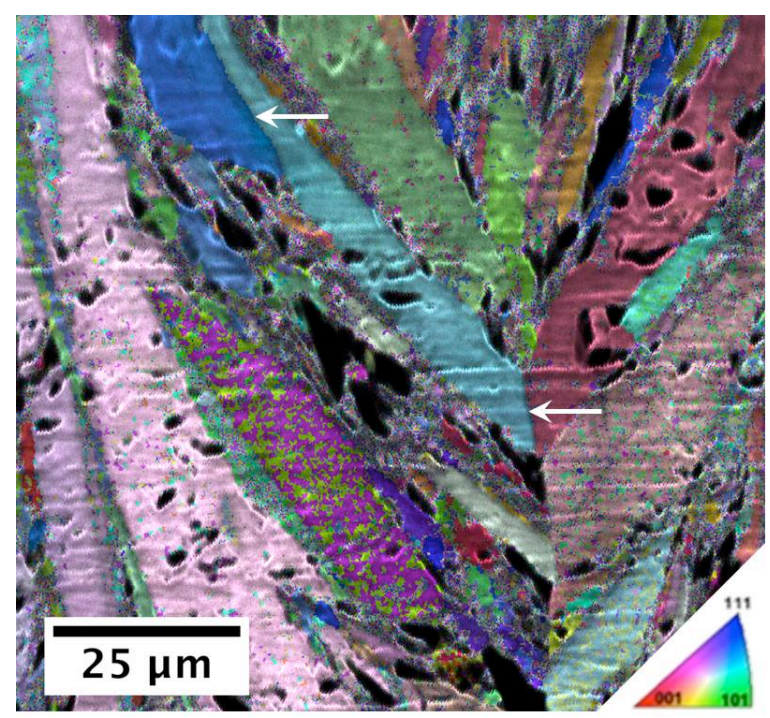

Fig. 12. EBSD inverse pole figure map overlaid on image quality background indicating a limited number of intact grain boundaries. White arrows highlight examples of intact grain boundaries. Black areas indicate unindexed points or points below index quality of 1000 that correspond to localized $\mathrm{SiC}$ dissolution.

\section{Mechanism of $\mathrm{SiC}$ recession kinetics}

While the Pourbaix diagram in Fig. 1 implies that silica is expected to form as a result of SiC reaction with high temperature water, the results presented in Sect. 4 underline an important fact regarding this product: it dissolves readily in high temperature water. This is evident from the much faster mass loss rate observed in silica specimens (Fig. 6) and the absence of any silica on the surface of SiC specimens. Fortunately, ample prior data are available on the kinetics of silica dissolution in water [46-51]. As explained in detail elsewhere [47], the net dissolution rate of silica, $r_{n e t}(\mathrm{~mol} / \mathrm{kg}-\mathrm{s})$ is given by

$r_{n e t}=k_{f} \frac{A}{M}\left(1-\frac{m}{m_{s a t}}\right)$,

where $k_{f}\left(\mathrm{~mol} / \mathrm{m}^{2}-\mathrm{s}\right), A\left(\mathrm{~m}^{2}\right), M(\mathrm{~kg}), m$, and $m_{\text {sat }}$ are the forward reaction rate constant, the surface area, the mass of water, the concentration of silica in water, and the solubility limit of silica in the water (Fig. 2), respectively. Given that the results described in Sect. 4 are from tests conducted in continuously flowing and filtered autoclaves, it is possible to assume that the concentration of silica in water $(\mathrm{m})$ during these tests is insignificant and to compare the mass loss rate to the literature data for $k_{f}$. Note that the mass loss is assumed to vary linearly with time. This exercise is carried out in Fig. 13 where literature data on dissolution rates of quartz and amorphous silica are compared to what was measured here for CVD-SiC (Fig. 4) and fused silica specimens (Fig. 6). Note that the literature reported rate of dissolution for amorphous silica was up to $250^{\circ} \mathrm{C}$ [50] and has been extrapolated to higher temperatures for the purposes of this study. This extrapolation results in a smaller apparent rate of dissolution of amorphous silica than that reported in [47] for quartz, while it is known that amorphous silica in fact dissolves faster than quartz at lower temperatures [50]. As shown in the figure, the mass loss rate for CVD-SiC specimens is at least two orders of magnitude smaller than literature data for silica dissolution, while the single data point from short-term tests on amorphous silica is in reasonable agreement with literature data. 


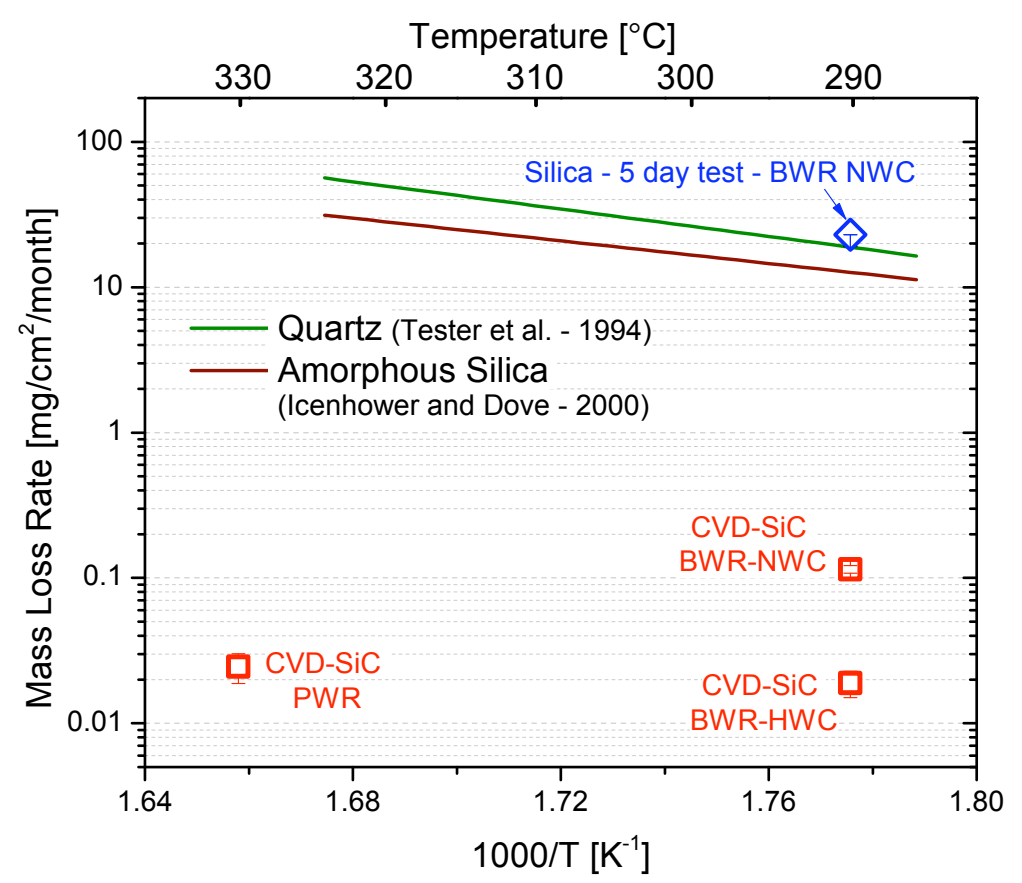

Fig. 13. Comparison between dissolution rates of quartz and amorphous silica from literature [47, 50] and the CVD$\mathrm{SiC}$ and fused silica examined in this study. Correlation for amorphous silica dissolution rate has been extrapolated to temperatures beyond the study in [50].

Figure 13 leads to an important conclusion, that the kinetics of $\mathrm{SiC}$ recession is not limited by silica dissolution but, rather, by silica formation. This is consistent with the results in Sect. 4, where no silica was found to be present on the surface of the specimens, since once it forms, it readily dissolves in water. Note that in Fig. 13 the recession kinetics at $290^{\circ} \mathrm{C}$ (BWR conditions) increases sixfold when the oxygen activity in the system is increased. The fact that oxygen activity is playing an important role in $\mathrm{SiC}$ recession kinetics is also consistent with the conclusion that silica dissolution is not the rate-limiting step for this process since it does not involve dissolved oxygen in the course of the dissolution reaction.

If the resulting silica is assumed to immediately dissolve away, the silica formation obeys interfacereaction-limited kinetics and, therefore, the rate of silica formation via reaction of water with $\mathrm{SiC}, r_{l}$, will have the general form

$r_{1}=k_{1}\left(a_{S i C}\right)\left(a_{H_{2} O}\right)^{n_{1}}$

where $k_{l}$ is the reaction rate constant and the other two terms on the right-hand side of the equation are the activities of $\mathrm{SiC}$ and water. $n_{1}$ is the order of reaction for water and can vary from 2 to 4 based on Eqs.

(1)-(4). At the reaction interface, $\mathrm{SiC}$ and water are abundantly available, so the activities are assumed to be unity and the value of $n_{1}$ becomes irrelevant. Silica can also form as a result of the reaction of dissolved oxygen with the $\mathrm{SiC}$ surface following one of these paths:

$$
\begin{aligned}
& \mathrm{SiC}_{(\mathrm{s})}+\mathrm{O}_{2(\mathrm{aq})} \rightarrow \mathrm{SiO}_{2(\mathrm{~s})}+\mathrm{C}_{(\mathrm{s})} \\
& \mathrm{SiC}_{(\mathrm{s})}+3 / 2 \mathrm{O}_{2(\mathrm{aq})} \rightarrow \mathrm{SiO}_{2(\mathrm{~s})}+\mathrm{CO}_{(\mathrm{g})} \\
& \mathrm{SiC}_{(\mathrm{s})}+2 \mathrm{O}_{2(\mathrm{aq})} \rightarrow \mathrm{SiO}_{2(\mathrm{~s})}+\mathrm{CO}_{2(\mathrm{~g})}
\end{aligned}
$$


While all these reaction routes are viable, the most negative Gibbs energy change under the conditions of interest for this study is associated with the reaction in Eq. (10). The rate of silica formation via reaction of dissolved oxygen with $\mathrm{SiC}, r_{2}$, will then have the general form

$r_{2}=k_{2}\left(a_{S i C}\right)\left(a_{O_{2}}\right)^{n_{2}}$.

Since the temperature, $\mathrm{pH}$, and pressure are identical in both BWR immersion tests, and assuming $n_{2}$ is 2 , it is possible to calculate the reaction rate constants, $k_{1}$ and $k_{2}$, from the data in Fig. 13 and Eqs. (7) and (11) if the oxygen activity is known. Figure 14 shows the activity of dissolved $\mathrm{OH}^{-}$and $\mathrm{O}_{2}$ inside the BWR and PWR autoclaves as a function of electrochemical potential. Note that oxygen activity in the BWR water increases by 30 orders of magnitude between HWC and NWC conditions. Table 3 shows the calculated reaction rate constants from the available dissolution rate data and calculated oxygen activities. Since oxygen activity is so low in the PWR immersion test, $k_{l}$ is assumed equal to the observed dissolution rate (also the case for the BWR-HWC immersion). The possibility of $\mathrm{SiC}$ oxidation by $\mathrm{OH}^{-}$ ions is ignored here and if it is impactful, it is bundled into the calculated $k_{l}$ value (since $\mathrm{OH}^{-}$activity is constant for the BWR tests). $k_{2}$ could not be calculated for the PWR case (higher temperature), as no high-oxygen test was performed. The increase of $k_{l}$ from the BWR to the PWR case allows calculation of an activation energy on the order of $\sim 18 \mathrm{~kJ} / \mathrm{mole}$, which is significantly lower than that reported by Deal and Grove for dry and wet oxidation of $\mathrm{Si}$ at higher temperatures [52]. The calculated activation energy is prone to large errors since only limited data are available and the effect of $\mathrm{OH}^{-}$activity, if any, is not accounted for. The important takeaway from this exercise is that dissolved oxygen can greatly increase $\mathrm{SiC}$ oxidation under these conditions.

Table 3. Calculated oxygen activity from Fig. 14 and $\mathrm{SiC}$ oxidation rate constants determined from measured rates in Fig. 13.

\begin{tabular}{|l|c|c|c|c|c|}
\hline & $\begin{array}{c}\text { Temperature } \\
\left({ }^{\circ} \mathbf{C}\right)\end{array}$ & $\begin{array}{c}\text { Measured rate } \\
\left(\mathbf{m g} / \mathbf{c m}^{2}-\mathbf{s}\right)\end{array}$ & $\boldsymbol{a}_{\mathbf{O} 2}$ & $\begin{array}{c}\boldsymbol{k}_{\mathbf{1}} \\
\left(\mathbf{m g} / \mathbf{c m}^{2}-\mathbf{s}\right)\end{array}$ & $\begin{array}{c}\boldsymbol{k}_{\mathbf{2}} \\
\left(\mathbf{m g} / \mathbf{c m}^{2}-\mathbf{s}\right)\end{array}$ \\
\hline PWR & 330 & $6.35 \times 10^{4}$ & $2.0 \times 10^{-36}$ & $6.35 \times 10^{4}$ & No data \\
\hline BWR-HWC & 290 & $4.90 \times 10^{4}$ & $2.0 \times 10^{-38}$ & \multirow{2}{*}{$4.90 \times 10^{4}$} & $8.60 \times 10^{16}$ \\
\hline BWR-NWC & 290 & $2.97 \times 10^{5}$ & $1.7 \times 10^{-6}$ & & \\
\hline
\end{tabular}




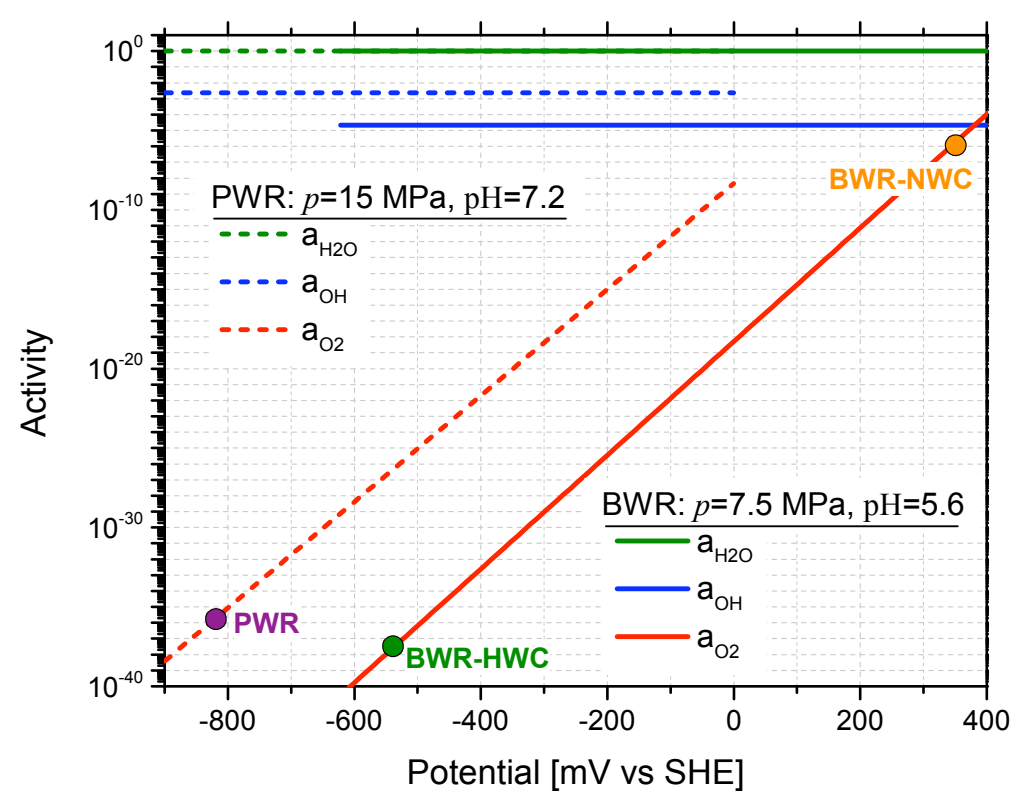

Fig. 14. Activity of water as well as dissolved $\mathrm{OH}^{-}$and $\mathrm{O}_{2}$ inside the $\mathrm{BWR}$ and $\mathrm{PWR}$ autoclaves as a function of electrochemical potential.

\section{Discussion}

\subsection{Effect of irradiation on SiC hydrothermal corrosion kinetics}

In recent years a number of studies have shown a clear difference between the corrosion rates of SiC without and with irradiation [7, 53-54]. Essentially a substantial increase has been consistently observed when irradiation is present. Irradiation is expected to increase the corrosion kinetics by two mechanisms: 1) increasing the oxygen activity in the water and 2) forming a highly defected $\mathrm{SiC}$ microstructure [55] that is more susceptible to corrosion. The effect of increased oxygen activity on the corrosion rate was discussed in Sect. 5. The mechanism for the increase in oxygen activity is radiolysis, which results in decomposition of water due to intense gamma and neutron irradiation. Aside from increasing oxygen activity in the system, radiolysis also produces many other metastable oxidizing species such as $\mathrm{H}_{2} \mathrm{O}_{2}$ and $\mathrm{HO}_{2}$. The effect of radiolysis becomes particularly pronounced in the absence of a HWC regime, where low hydrogen activity in the system is ineffective in scavenging and neutralizing these active oxidants.

The unique role of irradiated microstructure on enhancing corrosion kinetics of $\mathrm{SiC}$ is evident from the work of Kondo et al. [54], where ion irradiated specimens underwent immersion tests under BWR-NWC conditions in absence of any irradiation. A clear difference in corrosion rate of ion irradiated and unirradiated material was shown in that study. The increased susceptibility of irradiated SiC microstructure to irradiation is itself another piece of evidence to support the surface-reaction-limited corrosion (essentially oxidation) kinetics of $\mathrm{SiC}$ under hydrothermal conditions. If instead a silica layer was present at the surface (the case for steam oxidation of $\mathrm{SiC} \mathrm{[56]),} \mathrm{the} \mathrm{underlying} \mathrm{microstructure} \mathrm{of} \mathrm{SiC}$ would prove irrelevant in the corrosion process. A number of qualitative explanations exist for the enhancement of corrosion due to the presence of irradiation defects. Clear preferential attack was observed from microscopy results in Sect. 4.2.3, hinting that the different surface energetics (different crystallographic planes or the presence of defects such as grain or twin boundaries) is responsible for this phenomenon. Irradiation defects further increase the energy of the surface and can act as initiation sites 
for the oxidation reaction. Also, irradiation can result in development of stress in the material that can accelerate corrosion, with many references available dating back to initial work by Hillig and Charles [57]. The effect of stress should be considered paramount for ion irradiated SiC specimens, where a thin layer of material (a few micrometers) is under stresses on the order of $1 \mathrm{GPa}$ as evident from recent results by Kondo et al. [54].

\subsection{Silica dissolution inside a power loop}

In this section a simplified model of silica dissolution inside a power loop resembling a LWR system is developed. The model aims to show the effect of silica dissolution and subsequent deposition inside a power loop with temperature gradients. To model silica transport and deposition, a 60-m-long onedimensional loop meshed uniformly (20 cm mesh size) is assumed. Ignoring fluid viscosity and assuming an incompressible fluid with constant flow velocity, and instantaneous mixing of silica within each element of the 1D loop, the rate of mass change within each element is given by the following 1D advection equation:

$\frac{d m}{d t}=v \frac{d m}{d x}+r_{n e t}$,

where $m$ is the concentration of silica, $v$ is fluid velocity, and $r_{n e t}$ is the spatially variable net dissolution rate (source or sink term) as described in Eq. (6). The saturated solubility limit and the forward reaction rate constant in Eq. (6) are both temperature dependent and vary between the various elements.

Equation (12) is a first-order linear partial differential equation that can be discretized and solved efficiently by using an implicit upwind scheme. Since the problem involves advection of dissolved silica in a loop, one of the boundary conditions is the continuous flux at the loop ends, assuming they are positioned at $x=0$ :

$\left.v \frac{d m}{d x}\right|_{x=0^{+}}=\left.\frac{d m}{d x}\right|_{x=0^{-}}$.

A second condition necessary to solve this system of linear equations can be given by conservation of mass as follows:

$\int_{0}^{L} \int_{t}^{t+d t} r_{n e t} d t d x=\int_{0}^{L} m^{t+d t} d x-\int_{0}^{L} m^{t} d x$

where $L$ is the length of the loop. Equation (14) implies that the net silica added or removed from the loop during each time step due to dissolution or deposition, respectively, equals the change in total silica content in the loop.

Numerous simplifying assumptions used for this analysis differ from the actual primary loop parameters. However, this analysis is revealing with respect to general trends in the system and could be used as a guideline for future more detailed analyses. The 60-m-long loop is envisioned with a constant diameter of $2.5 \mathrm{~m}$ and a constant-speed water flow of $3 \mathrm{~m} / \mathrm{s}$ inside the vessel. The temperature profile along with the surface area-to-water mass ratio for this hypothetical power loop is plotted in Fig. 15. The surface area increases dramatically in the fuel and steam generator regions to resemble the large density of cladding and generator tubes in these regions, respectively. The saturated solubility limit for silica, also shown in 
that figure, is calculated by using Fournier and Rowe's correlation [30] at $15 \mathrm{MPa}$ pressure and given the temperature profile in the loop.

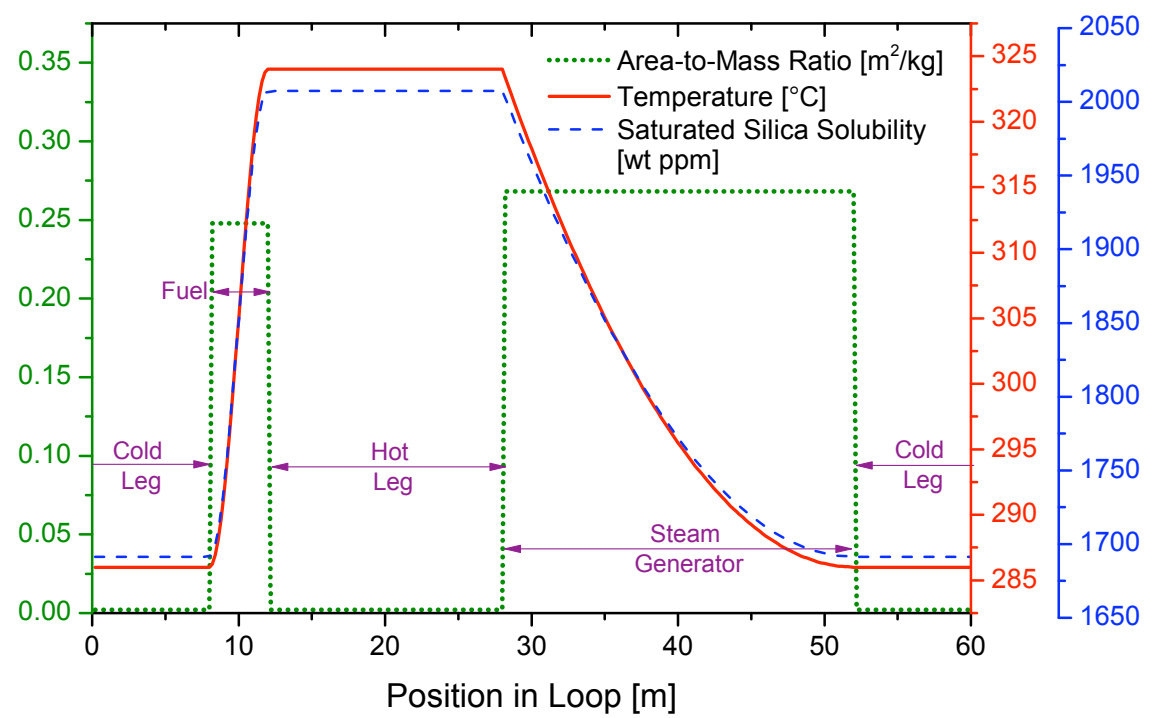

Fig. 15. Profiles of temperature, surface area-to-water mass ratio, and saturated solubility limit of silica along the loop length.

Once the loop is started, the concentration of dissolved silica builds up uniformly inside the loop even though the only source of silica at the start is the fuel region. This is the case because the flux term in Eq. (12) is much larger than the source term. Therefore, to estimate average dissolved silica concentration in the loop, one can ignore the flux term in Eq. (12), which is then reduced to

$\frac{d m}{d t}=\frac{1}{L} \int_{0}^{L} k_{f} \frac{A}{M} d x\left(1-\frac{m}{m_{\text {sat }}}\right)$.

Assuming at $t=0$ the dissolved silica concentration in the loop is zero, the solution of this differential equation is

$$
m=m_{\text {sat }}\left(1-\exp \left(\frac{-\frac{1}{L} \int_{0}^{L} k_{f} \frac{A}{M} d x t}{m_{\text {sat }}}\right)\right) .
$$

Figure 16 shows the average dissolved silica concentration in the loop as a function of time for various rates of silica dissolution in water. At the high extreme, the dissolution rate of amorphous silica in high temperature neutral water is used as reported by Icenhower and Dove [50] (also noted in Fig. 13) and quantified in Eq. (17):

$k_{f}\left[\frac{\mathrm{mg}}{\mathrm{cm}^{2} \mathrm{~s}}\right]=1.03 \times 10^{8} \exp \left(-\frac{75.4[\mathrm{~kJ}]}{R T[\mathrm{~K}]}\right)$.

Note that this worst-case scenario assumes that the silica dissolution rate is the rate-limiting step for corrosion of the $\mathrm{SiC}$ fuel cladding and may not be realistic. The figure also shows the same trends for dissolution rates one and two orders of magnitude smaller than this worst-case scenario, where the latter corresponds with the SiC corrosion rate measured under BWR-NWC conditions in this study. The average concentrations are calculated via Eq. (16) and compared with the average loop concentrations for 
the numerical model that takes into account the flux and the net source term at the same time. The numerical model also takes into account the variation in temperature and therefore the dissolution or deposition rates across the various positions along the loop and differs slightly from the ideal solution of Eq. (16). In all cases, silica concentration in the water increases to then saturate if and once it reaches the solubility limit. It is shown that in this hypothetical loop, the silica concentration does not reach the solubility limit after two years if $\mathrm{SiC}$ is undergoing corrosion, with kinetics measured in the autoclave tests conducted in Sect. 4. However, if irradiation enhances the corrosion kinetics (by at least an order of magnitude), a high silica concentration (approaching that of the solubility limit) could be expected.

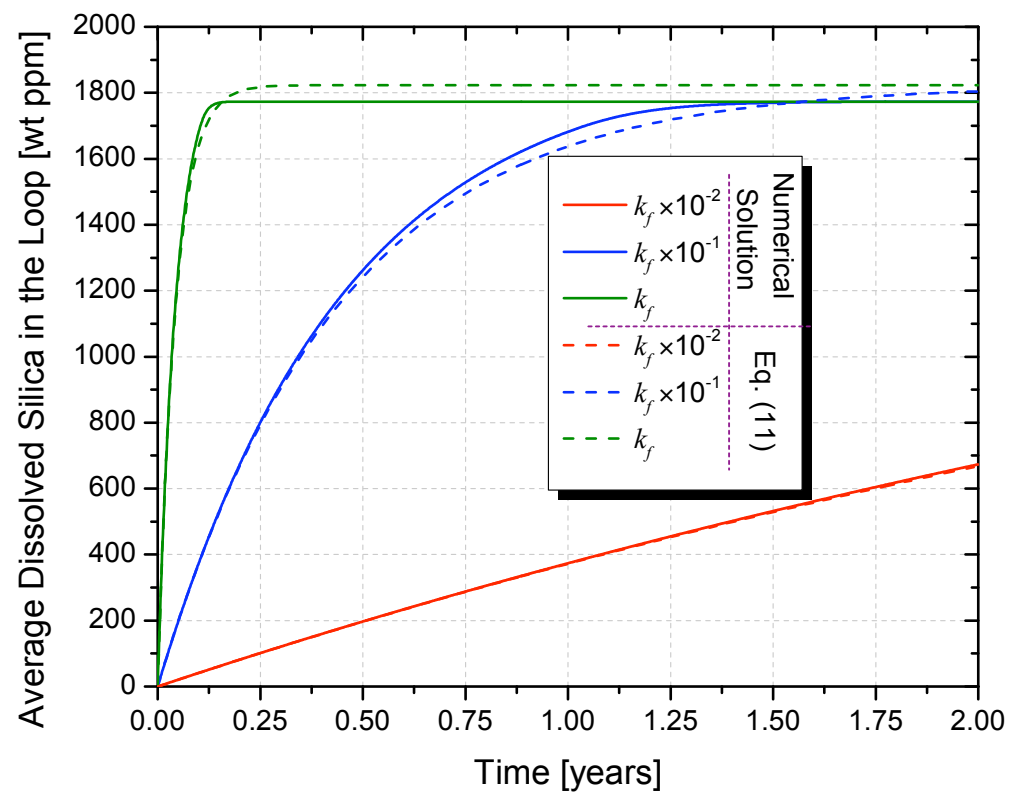

Fig. 16. Average dissolved silica concentration in the loop as a function of time for various rates of silica dissolution in water. $k_{f}$ is the amorphous silica dissolution rate taken from [50].

While the silica concentration in Fig. 16 increases quite uniformly across the loop, as explained earlier, the flux term is much larger than the source term in Eq. (12), and during short time scales the dynamic nature of position-dependent silica dissolution and transport in the loop cannot be ignored. Figure 17 shows the evolution of silica concentration across the loop at the onset of loop start-up, where $k_{f}$ is the amorphous silica dissolution rate taken from [50]. As shown in this figure, silica selectively dissolves from the fuel region and transports across the loop. The overall concentration then builds in distinct steps as the liquid travels the full length of the loop. 


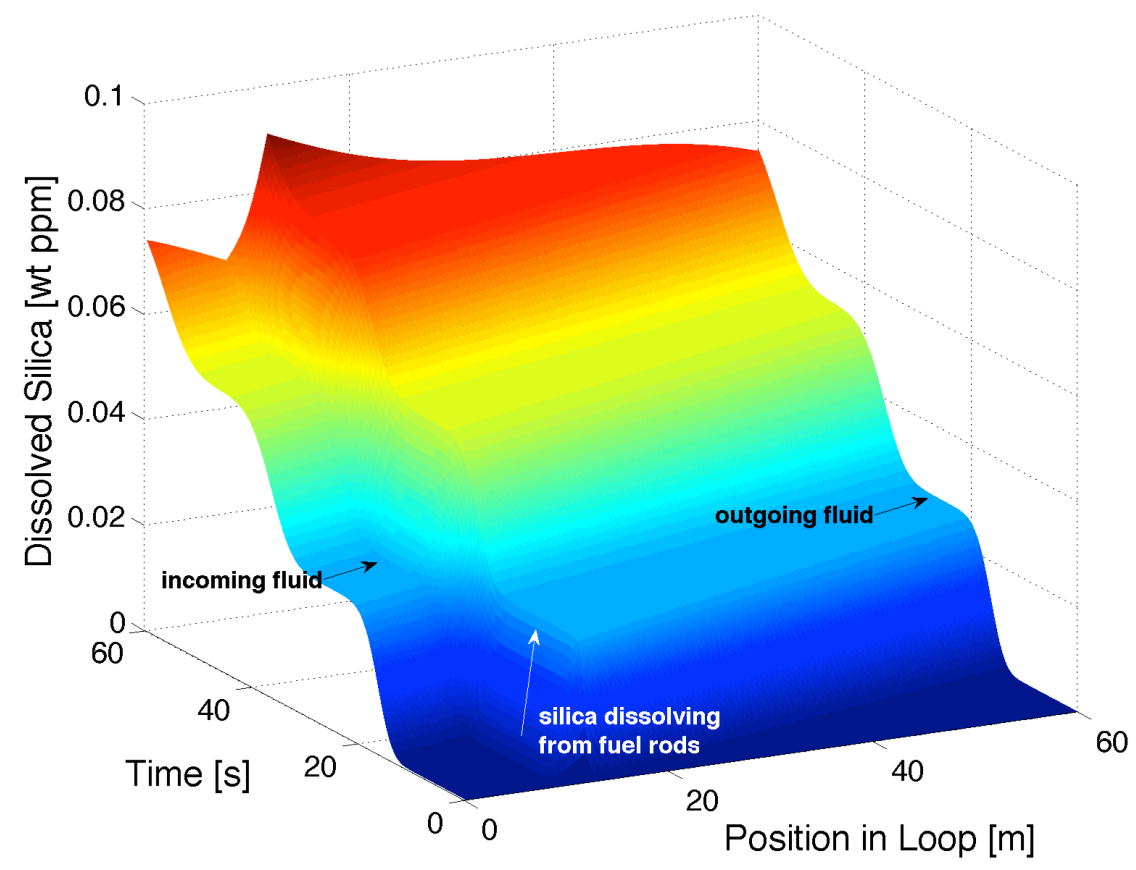

Fig. 17. Evolution of silica concentration in the loop as a function of time and position at the onset of loop start-up.

Once the silica concentration reaches its solubility limit in water, it will begin to deposit in the colder regions of this hypothetical loop. The mass per unit area of deposited silica plotted in Fig. 18 can also be converted to silica layer thickness. In the figure, assuming a uniform and dense silica layer $\left(2.2 \mathrm{~g} / \mathrm{cm}^{3}\right)$, every $10 \mathrm{mg} / \mathrm{cm}^{2}$ of silica corresponds to a $45 \mu \mathrm{m}$ layer thickness. Figure 18 indicates that silica mostly deposits towards the end of the steam generator and along the cold leg. It is also possible to estimate the thickness loss from the $\mathrm{SiC}$ cladding. Assuming a dense $\mathrm{SiC}\left(3.2 \mathrm{~g} / \mathrm{cm}^{3}\right.$, which is much higher than the density of $\mathrm{SiC} / \mathrm{SiC}$ [of order $2.2 \mathrm{~g} / \mathrm{cm}^{3}$ ]), the cladding thickness loss after 2 years is calculated and shown in Fig. 19. Note that for rapid SiC dissolution rates, silica builds up in the coolant and eventually deposits on the colder regions of the cladding.

The constant assumption during the analysis in this section is that dissolved silica is not removed from the loop via any filtration process. This implies that the degree of undersaturation, $\left(1-\mathrm{m} / \mathrm{m}_{\text {sat }}\right)$ in Eq. (6), decreases with time and nearly approaches zero when the average solubility limit in the loop has been reached. Therefore, the kinetics of dissolution is greatly reduced with time under these circumstances. However, if a method for removing silica from the loop is implemented, dissolution is accelerated, and cladding thickens, then the loss will be higher than that estimated in Fig. 19. 


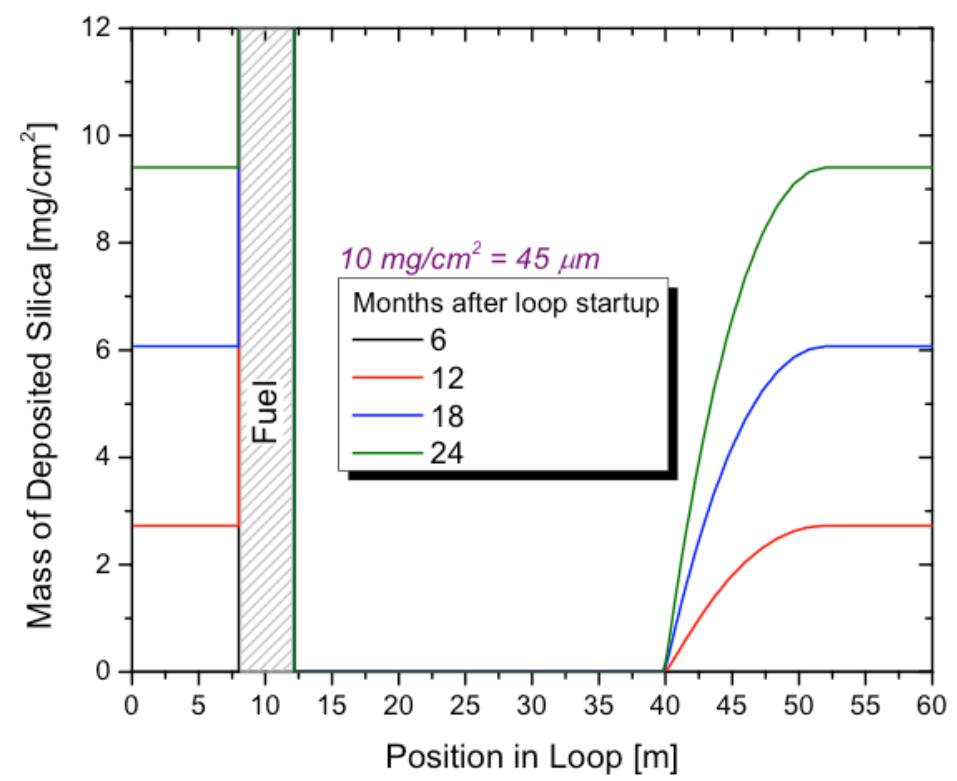

Fig. 18. Areal density of deposited silica within the loop at different times and $\mathrm{SiC}$ dissolution rates.

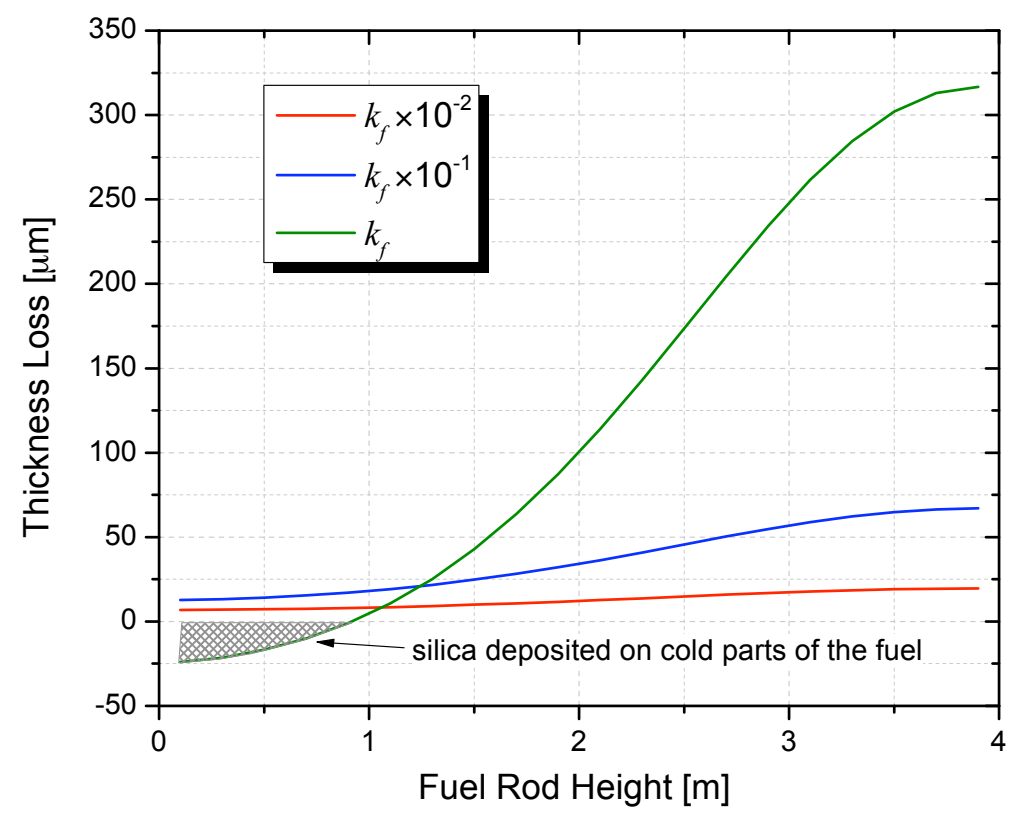

Fig. 19. Cladding thickness loss after 2 years for different SiC dissolution rates.

\section{Conclusions}

The following major conclusions can be drawn from the results and analysis in this paper:

- A thermodynamic driving force always exists for the silicon in $\mathrm{SiC}$ to undergo oxidation and produce silica in hydrothermal LWR coolant environments.

- Once silica forms under hydrothermal conditions, it readily dissolves in water. 
- The kinetics of $\mathrm{SiC}$ recession under hydrothermal conditions is surface-oxidation-reaction limited (reaction of oxidizing species with $\mathrm{SiC}$ to form silica).

- The dissolved oxygen activity in water can greatly increase $\mathrm{SiC}$ recession since it has a large reaction rate constant.

- In fuel cladding applications, depending on the in-pile recession kinetics of $\mathrm{SiC}$, loss of cladding thickness can potentially expose the fiber-matrix interphase and allow the silica concentration in the coolant to build up to the point of saturation, after which it can deposit in the cold regions of the power loop.

\section{Acknowledgments}

C.M. Silva, X. Hu, Y. Katoh, B. Pint, J. Busby, and L. Snead at ORNL contributed to the experimental investigations and offered useful discussions. T. Koyanagi and C. Ang at ORNL provided useful comments on the manuscript. The work presented in this paper was supported by the Advanced Fuels Campaign of the Fuel Cycle R\&D program in the Office of Nuclear Energy, US Department of Energy.

\section{References}

[1] H. Nickel; H. Nabielek; G. Pott; A. Mehner, Nuclear Engineering and Design 2002, 217 (1), 141-151.

[2] D. Petti; J. Maki; J. Hunn; P. Pappano; C. Barnes; J. Saurwein, et al., JOM Journal of the Minerals, Metals and Materials Society 2010, 62 (9), 62-66.

[3] Y. Katoh; L. L. Snead; C. H. Henager, Jr.; A. Hasegawa; A. Kohyama; B. Riccardi, et al., Journal of Nuclear Materials 2007, 367-370, 659-671.

[4] Y. Katoh; L. L. Snead; C. Henager; T. Nozawa; T. Hinoki; A. Iveković, et al., Journal of Nuclear Materials 2014, 455 (1), 387-397.

[5] H. Feinroth, Gamma Engineering Report GN-54-03 2005.

[6] K. Yueh; D. Carpenter; H. Feinroth, Nuclear Engineering International 2010, 55 (666), 14-16.

[7] D. M. Carpenter. An assessment of silicon carbide as a cladding material for light water reactors. Massachusetts Institute of Technology, 2010.

[8] W.-J. Kim; D. Kim; J. Y. Park, Nucl. Eng. Technol 2013, 45 (4), 565-72.

[9] Y. Katoh; K. A. Terrani; L. L. Snead Systematic Technology Evaluation Program for SiC/SiC Composite-based Accident-Tolerant LWR Fuel Cladding and Core Structures; Oak Ridge National Laboratory (ORNL): 2014.

[10] F. Ford; B. Gordon; R. Horn, Corrosion in boiling water reactors. In ASM Handbook, 2006; Vol. 13, p 341.

[11] P. Scott; P. Combrade, Corrosion in Pressurized Water Reactors. In ASM Handbook, 2006; Vol. 13, p 362.

[12] P. Andresen; K. Arioka; S. Bruemmer; J. Busby; R. Dyle; P. Ford, et al. Expanded Materials Degradation Assessment (EMDA), Volume 2: Aging of Core Internals and Piping Systems, NUREG/CR-7153, Vol. 2, ORNL/TM2013/532; US Nuclear Regulatory Commission: 2013.

[13] M. Yoshimura; J.-i. Kase; S. Sōmiya, Oxidation of SiC powder by high-temperature, high-pressure H2O. In Hydrothermal Reactions for Materials Science and Engineering, Springer: 1989; pp 390-393.

[14] H. Hirayama; T. Kawakubo; A. Goto; T. Kaneko, Journal of the American Ceramic Society 1989, 72 (11), 2049-2053.

[15] Y. Gogotsi; M. Yoshimura, Journal of materials science letters 1994, 13 (6), 395-399.

[16] T. Kraft; K. Nickel; Y. Gogotsi, Journal of materials science 1998, 33 (17), 4357-4364.

[17] S. Sōmiya, Materials chemistry and physics 2001, 67 (1), 157-164.

[18] W.-J. Kim; H. S. Hwang; J. Y. Park; W.-S. Ryu, Journal of materials science letters 2003, 22 (8), 581-584.

[19] C. H. Henager; A. L. Schemer-Kohrn; S. G. Pitman; D. J. Senor; K. J. Geelhood; C. L. Painter, Journal of Nuclear Materials 2008, 378 (1), 9-16.

[20] V. Presser; K. G. Nickel, Critical Reviews in Solid State and Materials Sciences 2008, 33 (1), 1-99. 
[21] V. Presser; K. Nickel; O. Krummhauer; A. Kailer, Wear 2009, 267 (1), 168-176.

[22] J.-Y. Park; I.-H. Kim; Y.-I. Jung; H.-G. Kim; D.-J. Park; W.-J. Kim, Journal of Nuclear Materials 2013, 443

(1-3), 603-607.

[23] E. Barringer; Z. Faiztompkins; H. Feinroth; T. Allen; M. Lance; H. Meyer, et al., Journal of The American Ceramic Society 2007, 90 (1), 315-318.

[24] B. Sundman; B. Jansson; J.-O. Andersson, Calphad 1985, 9 (2), 153-190.

[25] Y. G. Gogotsi; M. Yoshimura, 1994.

[26] N. S. Jacobson; Y. G. Gogotsi; M. Yoshimura, J. Mater. Chem. 1995, 5 (4), 595-601.

[27] A. Hashimoto, Geochimica et cosmochimica acta 1992, 56 (1), 511-532.

[28] N. S. Jacobson; E. J. Opila; D. L. Myers; E. H. Copland, The Journal of Chemical Thermodynamics 2005, 37 (10), 1130-1137.

[29] A. V. Plyasunov, Geochimica et Cosmochimica Acta 2011, 75 (13), 3853-3865.

[30] R. O. Fournier; J. J. Rowe, Am. Mineral. 1977, 62, 1052-1056.

[31] R. K. Iler, The chemistry of silica. Wiley, New York: 1979.

[32] R. O. Fournier; R. W. Potter II, Geochimica et Cosmochimica Acta 1982, 46 (10), 1969-1973.

[33] I. Gunnarsson; S. Arnórsson, Geochimica et Cosmochimica Acta 2000, 64 (13), 2295-2307.

[34] M. P. Verma, Geothermics 2000, 29 (3), 323-346.

[35] T. V. Gerya; W. V. Maresch; M. Burchard; V. Zakhartchouk; N. L. Doltsinis; T. Fockenberg, European Journal of Mineralogy 2005, 17 (2), 269-283.

[36] P. M. Dove; N. Han; J. J. De Yoreo, Proceedings of the National Academy of Sciences of the United States of America 2005, 102 (43), 15357-15362.

[37] B. R. Bickmore; J. C. Wheeler; B. Bates; K. L. Nagy; D. L. Eggett, Geochimica et Cosmochimica Acta 2008, $72(18), 4521-4536$.

[38] L. W. Hobbs, Nuclear Instruments and Methods in Physics Research Section B: Beam Interactions with Materials and Atoms 1994, 91 (1), 30-42.

[39] B. Fleming; D. Crerar, Geothermics 1982, 11 (1), 15-29.

[40] T. Seward, Geochimica et Cosmochimica Acta 1974, 38 (11), 1651-1664.

[41] Fuel Reliability Guidelines: PWR Fuel Cladding Corrosion and Crud, No. 3002002795; Electric Power Research Institute: 2014.

[42] C.-T. A. Chen; W. L. Marshall, Geochimica et Cosmochimica Acta 1982, 46 (2), 279-287.

[43] F. Amy; Y. J. Chabal, Journal of chemical physics 2003, 119, 6201-6209.

[44] W.-J. Kim; D. Kim; J. Y. Park, Environmental Effect on the Oxidation of CVD SiC Ceramics and Composites. In 37th International conference and exposition on advanced ceramics and composites, Daytona Beach, FL, 2013.

[45] G. Palumbo; E. Lehockey; P. Lin, JOM 1998, 50 (2), 40-43.

[46] B. A. Fleming, Journal of colloid and interface science 1986, 110 (1), 40-64.

[47] J. W. Tester; W. G. Worley; B. A. Robinson; C. O. Grigsby; J. L. Feerer, Geochimica et Cosmochimica Acta 1994, 58 (11), 2407-2420.

[48] P. M. Dove, American Journal of Science 1994, 294 (6), 665-712.

[49] P. M. Dove, Geochimica et Cosmochimica Acta 1999, 63 (22), 3715-3727.

[50] J. P. Icenhower; P. M. Dove, Geochimica et Cosmochimica Acta 2000, 64 (24), 4193-4203.

[51] P. M. Dove; N. Han; A. F. Wallace; J. J. De Yoreo, Proceedings of the National Academy of Sciences 2008, 105 (29), 9903-9908.

[52] B. E. Deal; A. Grove, Journal of Applied Physics 1965, 36 (12), 3770-3778.

[53] S. Kondo; M. Lee; T. Hinoki; Y. Hyodo; F. Kano In Hydrothermal corrosion of ion irradiated SiC, 38th International conference and exposition on advanced ceramics and composites, Daytona Beach, FL, Daytona Beach, FL, 2014.

[54] S. Kondo; M. Lee; T. Hinoki; Y. Hyodo; F. Kano, Journal of Nuclear Materials 2015, doi: 10.1016/j.jnucmat.2015.04.034.

[55] L. L. Snead; T. Nozawa; Y. Katoh; T. S. Byun; S. Kondo; D. A. Petti, Journal of Nuclear Materials 2007, 371 (1-3), 329-377.

[56] K. A. Terrani; B. A. Pint; C. M. Parish; C. M. Silva; L. L. Snead; Y. katoh, Journal of American Ceramic Society 2014, 97 (8), 2331-2352.

[57] W. Hillig; R. Charles, High strength materials 1965, 682-705. 